ERC Working Papers in Economics 05/01 May 2005

\title{
The Determinants of Return Intentions of Turkish Students and Professionals Residing Abroad: An Empirical Investigation
}

\author{
Nil Demet Güngör \\ Economics Department \\ Middle East Technical University \\ Ankara 06531 Turkey \\ e-mail: ngungor@metu.edu.tr \\ Aysit Tansel \\ Economics Department \\ Middle East Technical University \\ Ankara 06531 Turkey \\ e-mail: atansel@metu.edu.tr
}




\title{
The Determinants of Return Intentions of Turkish Students and Professionals Residing Abroad: An Empirical Investigation*
}

\author{
Nil Demet Güngör \\ Economics Department, Middle East Technical University \\ Ankara 06531 Turkey \\ Phone: + 903122102022 \\ Fax: +903122101244 \\ E-mail: ngungor@metu.edu.tr \\ Aysit Tansel \\ Economics Department, Middle East Technical University \\ Ankara 06531 Turkey \\ Phone: +90 3122102057 \\ Fax: +903122101244 \\ E-mail: atansel@metu.edu.tr
}

\begin{abstract}
The study estimates an empirical model of return intentions using a dataset compiled from an internet survey of Turkish professionals and Turkish students residing abroad. In the migration literature, wage differentials are often cited as an important factor explaining skilled migration. The findings of the study suggest, however, that other factors are also important in explaining the non-return of Turkish professionals. Economic instability in Turkey is found to be an important push factor, while work experience in Turkey also increases non-return. In the student sample, higher salaries offered in the host country and lifestyle preferences, including a more organized environment in the host country, increase the probability of not-returning. For both groups, the analysis also points to the importance of prior intentions and the role of the family in the decision to return to Turkey or stay overseas.
\end{abstract}

\footnotetext{
* The study is based in part on the Ph.D. thesis of Nil Demet Güngör, supervised by Dr. Aysit Tansel in the Economics Department of Middle East Technical University. The authors gratefully acknowledge the support of the Turkish Academy of Sciences Fellowship Program for doctoral studies and the financial support of the METU Research Fund, coded AFP-2000-4-03-06.
} 


\title{
The Determinants of Return Intentions of Turkish Students and Professionals Residing Abroad: An Empirical Investigation
}

\begin{abstract}
The study estimates an empirical model of return intentions using a dataset compiled from an Internet survey of Turkish professionals and Turkish students residing abroad. In the migration literature, wage differentials are often cited as an important factor explaining skilled migration. The findings of the study suggest, however, that other factors are also important in explaining the non-return of Turkish professionals. Economic instability in Turkey is found to be an important push factor, while work experience in Turkey also increases non-return. In the student sample, higher salaries offered in the host country and lifestyle preferences, including a more organized environment in the host country, increase the probability of not-returning. For both groups, the analysis also points to the importance of prior intentions and the role of the family in the decision to return to Turkey or stay overseas.
\end{abstract}

\section{Introduction}

The migration of highly educated individuals is often considered to be an expensive "gift" given by the developing world to the economically advanced countries, since the developed countries reap the benefits of developing countries' investments in education at apparently little cost. In the human capital approach to migration, the expected wage differential between the host and source countries is cast as the key determinant of skilled migration. Expected wage levels are tied not only to the prevailing incomes in various occupations, but also to the job opportunities that exist within professions. In addition, the individual migration decision is believed to be motivated by a number of "pull" factors, such as favorable compensation packages, a world-class work environment, better living conditions, active recruitment by employers and so on, and in part by "push" factors that originate in the home country that may include political instability, cost of living/inflation, and the inability to find work.

The focus of the study is on the determinants of skilled migration from Turkey, a middle income country that ranks $24^{\text {th }}$ among the top sending countries according to UN sources. Turkey is also among the top ten in terms of the number of students studying in US higher education institutions, along with much more populous countries such as India and China 
(IIE, 2001). These are indications that gross human capital transfer out of Turkey may be quite significant. While the "brain drain" phenomenon is not a new one for Turkey, the media and policymakers in Turkey have turned greater attention to the loss of Turkey's educated workforce in recent years in the aftermath of the economic crises in November 2000 and February 2001, where a third of the educated workforce became unemployed (Işı ğıçok, 2002).

The paper presents an empirical investigation of the return intentions of two separate, but related groups: university-educated Turkish professionals working abroad and Turkish students studying abroad. Among the participants in the first group, a significant number have earned their highest degree in the country they are currently working, and are therefore part of the phenomenon of student non-return. Those who earned their highest degree in Turkey may be viewed as being part of the brain drain in the traditional sense. An important difference between skilled migration and student non-return is that in the latter case, advanced education is received through the foreign university system, which is generally believed to be geared toward the labour market needs of the host country, which means that employability in the home country may be a greater concern for the second group (Chen and $\mathrm{Su}, 1995)$.

Many empirical studies of the brain drain rely on data obtained from questionnaire responses or face-to-face interviews. Some of these include studies on the Asian engineering brain drain (Niland, 1970), studies on China (Kao and Lee, 1973; Zweig and Changgui, 1995), and on Latin America (Cortés, 1980). Studies focusing on the Turkish brain drain include Oğuzkan $(1971,1975)$ and Kurtuluş (1999). Oğuzkan's study is based on a survey conducted in 1969 of 150 respondents holding a doctorate degree and working abroad. The study by Kurtuluş looks at the responses of 90 students studying in the United States in 1991. The current study on the return intentions of Turkish professionals and students residing abroad is based on a survey conducted by the authors during the first half of 2002 , which resulted in over 2000 responses. 
The information collected through the Internet survey is used to determine the empirical importance of various factors on the return intentions of the targeted populations. Section II presents a brief discussion of the survey methodology and provides details of the model selection and estimation procedures. The empirical specification of the model and the explanatory variables used in the empirical analysis are given in Section III. This is followed by the empirical investigation of the determinants of return intentions of Turkish professionals and other skilled workers in Section IV, Part A and by a similar analysis in Section IV, Part B for Turkish students studying abroad. Section V concludes.

\section{Methodology}

As mentioned, the results of the current study are based on data from an internet survey collected by the authors during the first half of 2002. The survey methodology is described in detail in Appendix A, Part A.1. In the econometric analysis of return intentions described in this section, we set out to determine the factors that are significant in explaining the migration of university-educated workforce and the non-return of students.

The dependent variable is the likelihood of returning to Turkey based on the response to the question "What are your current intentions about returning to Turkey?". Table 1 shows the possibilities presented to respondents in the Turkish professionals survey and for the student survey. The choices forming the categories of the dependent variable "likelihood of returning to Turkey" are slightly different in the student survey.

These choices form a set of ordered categories in which each consecutive category indicates an increase in intensity in the respondents' intentions to stay in their current country of residence. Because of the way the index is constructed, categories with a higher index value imply a greater intensity in feeling about not returning (staying). This means that positive coefficients on the independent variables indicate an increase in the probability of 
"not returning", while negative coefficients imply an increase in the probability of "returning".

Table 1

Dependent Variable, Return Intentions

\begin{tabular}{llc}
\hline Response Categories & Label & Index \\
\hline Professionals & & \\
I will definitely return and have made plans to do so. & $D R P$ & 1 \\
I will definitely return but have not made concrete plans to do so. & $D R N P$ & 2 \\
I will probably return. & $R P$ & 3 \\
I don't think that I will be returning. & $R U$ & 4 \\
I will definitely not return. & $D N R$ & 5 \\
Students & & \\
I will return as soon as possible without completing my studies. & $R_{-} B S$ & 1 \\
I will return immediately after completing my studies. & $R_{-} I A S$ & 2 \\
I will definitely return but not soon after completing my studies. & $R_{-} N S A S$ & 3 \\
I will probably return. & $R P$ & 4 \\
I don't think that I will be returning. & $R U$ & 5 \\
I will definitely not return. & $D N R$ & 6 \\
\hline
\end{tabular}

However, the change in intensity between categories cannot be assumed to be uniform. Given the ordered and non-uniform nature of these choices, the appropriate model is an ordered response model (Maddala, 1983). Formally, the observed discrete index is given by

$$
y_{i}=\{1,2,3, \ldots, J\}
$$

where $i$ indexes the observations and $J$ is the number of categories of the dependent variable. It is assumed that a continuous, latent variable underlies the discrete, ordered categories. This latent variable is explained by a set of observed characteristics and a random element as given below:

$$
y_{i}^{*}=\beta X_{i}+u_{i}
$$

where $y^{*}$ is the unobserved "return intention" variable, $X$ is the $(k \times 1)$ vector of explanatory variables, $\beta$ is the parameter vector to be estimated and $u$ is the random disturbance term. The 
relationship between the discrete, observed $y$ and unobserved, continuous $y^{*}$ is given as follows:

$$
y_{i}=\left\{\begin{array}{l}
1 \text { if } y_{i}^{*} \leq 0\left(=\mu_{1}\right) \\
2 \text { if } 0<y_{i}^{*} \leq \mu_{2} \\
3 \text { if } \mu_{2}<y_{i}^{*} \leq \mu_{3} \\
4 \text { if } \mu_{3}<y_{i}^{*} \leq \mu_{4} \\
\cdots \\
J \text { if } \mu_{J-1} \leq y_{i}^{*}
\end{array}\right.
$$

where $\mu_{1}, \mu_{2}, \mu_{3} \ldots \mu_{J-1}$ are the threshold parameters linking $y$ to $y^{*}$, which are estimated along with the explanatory variable coefficients. The ordered probit specification, which assumes an underlying normal distribution for the error term, is used in this study to estimate the model of return intentions. Given an ordered probit specification, the probability that an observed response falls into an arbitrary category $j$ is given below as:

$$
\operatorname{Prob}\left(y_{i}=j\right)=\Phi\left(\mu_{j}-\beta^{\prime} x_{i}\right)-\Phi\left(\mu_{j-1}-\beta^{\prime} x_{i}\right)
$$

where $\Phi($.$) is the cumulative normal distribution. Differentiating this probability with respect$ to the explanatory variables gives the marginal effect of each on the probability of choosing category $j$. Model estimation is carried out by using maximum likelihood (ML) estimation techniques since it has been shown that ML gives unbiased and efficient estimates for nonlinear models. Please refer to Appendix A, part A.2 for further details of choice of estimation methodology.

\section{Empirical Specification of the Model: Explanatory Variables}

\section{Income Differentials and other Push-Pull Factors:}

Given the importance of perceptions in making the migration decision, a set of "subjective" variables are used to determine the significance of various economic and social factors. These include the respondents' rankings of various push-pull factors in terms of their importance in their intention to return or stay. 
According to human capital theory, the difference in the expected foreign and domestic income levels is the key determinant of skilled migration. To account for the pecuniary aspect of the migration decision, "lack of a satisfactory income level in the home country" was included among the push factors and a "competitive income level in the current country of residence" was included as a pull factor (pushA and pullA). The approach of using these two subjective measures to test the impact of income differences may be justified by the fact that each migrant may have different perceptions of the income differential based on incomplete information of all alternative employment opportunities available to him or her. Not everyone may be equally informed of the prevailing income differentials, and more importantly, they may not place equal weight or importance to the same information. Another difficulty in using actual income differences is that it would require income information for a diverse range of occupations, and comparisons across countries would also need to take into account cost-ofliving differences.

Since expected income is the relevant variable, employment opportunities and labor market conditions both at home and abroad may play an important role in the perceptions of economic opportunity held by skilled individuals. General economic conditions and economic stability will determine relative employment opportunities and can lower or increase an individual's expected income accordingly. Economic instability and uncertainty in the home country was included among the Likert scale items as a push factor (pushK). This variable is expected to have a strong deterring effect on return intentions for the sample considered since at the time of the survey the Turkish economy was experiencing the effects of the 2001 economic crisis.

Gender Effects: The dummy variable for gender, female, takes on the value 1 for "female" and 0 for "male". In previous empirical studies, women have been found to be more reticent about returning to their homelands. In the case of China (Zweig and Changgui, 1995: 
36-7), for example, this is believed to be caused by a lack of career opportunities for women (e.g., the biases they face in the workplace) and constraints imposed on their behavior in China, as well as certain convenience factors abroad, aside from greater wage levels, that offer them a more comfortable lifestyle than they could expect to experience in China. These factors, including less lifestyle freedom, may also be important for women in Turkey making them less willing to return. According to one respondent:

I had all the intentions of returning at the end of my PhD. When I left Turkey I was 24 and had been married for three years. Toward the end of my $\mathrm{PhD}$ I got a divorce at the age of 26. In 1986, Turkey was not ready to accept the notion of a 26 year old divorced woman living by herself. My family expected me to live with them. That was not acceptable to me. Even today I do not feel that I would be as comfortable (or receive the same amount of respect I get in the USA) living in Turkey as a divorced 42 year old.

Age: "Age" and "Age squared" are included as explanatory variables in order to control for cohort effects and possible nonlinearities. Previous empirical research has established age as an important factor in determining the net present value of migration. Older workers tend to be less mobile than younger workers since the "psychic costs" of moving increase with age (Stark and Bloom, 1985). Older participants in the sample of professionals may therefore be expected to indicate a greater intention of remaining in the host country. However, those approaching retirement may be expected to exhibit stronger return intentions than younger participants who face a longer time frame for working and earning a high salary level in the foreign country.

Initial Return Intentions: Respondents were asked about their initial return intentions prior to going abroad to work or study. The possible responses were "return", "undecided" and "stay". Two dummy variables, init_UNSURE and init_RETURN, are included in the model to determine whether differences in the initial intention of the respondent prior to his/her venture abroad is important in determining his/her current intentions about returning to Turkey. "Stay" is chosen as the reference category. It is expected that respondents who left 
Turkey with the intention to return will be more likely to express the same intention at the time of filling out the survey.

Marital Status and Family Support: Family considerations are also expected to have considerable weight in the mobility decision of individuals. The marital status of respondents is included as an explanatory variable to account for family constraints. The effect of this variable on return intentions can work in either direction. Marriage to a foreign spouse is expected to reduce return intentions, while marriage to a Turkish spouse may either reduce or increase return intentions depending on the spouse's preferences and position in the family. The respondents were asked about the attitudes of their families both in terms of their initial decision to go abroad (fam_supl) and in terms of settling down permanently in their current location (fam_sup2). In a family-oriented culture, family attitudes may be expected to have a significant impact on the return decision of respondents. Both of the family support variables are ordinal categorical variables, which are treated as interval variables in the econometric model whenever appropriate (e.g. this decision is based on whether the null hypothesis of evenly spaced categories is rejected by a likelihood ratio test).

Stay Duration: Stay duration, represented by staydur, is the number of years spent in the current country. When stay duration increases, the incentive to return is expected to diminish, since individuals become more accustomed to living abroad. Thus, there may be an "inertial effect" with an increase in the length of stay. Longer stay duration may also be indicative of a preference to live abroad, whether existing initially or acquired with time. Since the stay duration variable also incorporates the effects of age, initial preferences and work experience, controlling for these variables will reveal the "pure inertial effects" of stay duration. According to one survey participant, finding a job in Turkey is dependent on informal networks and the longer one stays abroad the greater is their exclusion from these networks. Others have indicated that re-adapting to Turkey can be as difficult as the initial 
adjustment to a foreign culture when stay duration increases, since they believe social change occurs "much faster in Turkey".

Years of Work Experience: The number of years of work experience is believed to contribute to the general skills level of the respondents, which is believed to increase mobility. Goss and Paul (1986), argue that when the number of years of work experience is not controlled for, the coefficient on the "age" variable will be the sum of two countervailing factors. If the distinction between work experience in the home country versus in the foreign country is important for return intentions, then the number of years of work experience abroad may be the more pertinent variable (Wong, 1995), since this implies that respondents with greater overseas work experience will have acquired skills that are related to the capital stock of the host countries.

Wong's (1995) model of brain drain based on learning-by-doing interprets the greater output level in the host country as representing a cumulative base of experience. Foreign workers choosing to stay in the host country are able to take advantage of the greater base of experience and increase their productivities from learning-by-doing. This model can be tested by including the variable "number of years of overseas work experience" in the model (yrs_wrkd_abrd) or the number of years of experience in current country of residence (yrs_wrkd_cc) in the professionals survey. Return intentions are expected to decline as the number of years spent working abroad increases. If this is the case, Wong's learning by doing model will receive confirmation.

Occupation and Work Activities: A distinction can be made between academic and non-academic occupations. A dummy variable representing working in academia (or plans for working in academia in the case of students) was constructed to determine whether academicians are more or less likely to return than those in other occupations. Respondents were also asked to give the percentage of time they spend on various job-related activities. 
The first three job activities (basic research, applied research and development) are R\&D activities (OECD, 1994). The other activities considered are technical support, administrative and various other activities. These activities have been used as part of the National Science Foundation (NSF) Survey of Doctorate Recipients in the US (NSF, 1997). If respondents devoted at least half their time on $R \& D$ activities, they are labeled as $R \& D$ workers and placed in the R\&D category. A dummy variable, $R \& D$ ( 1 if $R \& D$ worker, 0 otherwise), is used to represent the effect of being involved in research and development activities overseas. It is expected that respondents involved in activities related to research and development will have weaker return intentions, since they are doing very specialized work that may be difficult to duplicate or develop in Turkey.

Previous Overseas Experience: Prior overseas experience (work, study or travel) before coming to the current country of residence may be an influential factor in adjusting to or feeling comfortable with the current country of stay. Some of those with previous overseas experience who returned to Turkey to work for a period of time have also had the opportunity to compare the work environments and therefore base their return decisions on this comparison. In addition to prior experience overseas, various adjustment factors were included in the questionnaire, including having a large Turkish community in the city of residence. These factors and difficulties faced while abroad are included in the model as dummy variables.

Level and Location of Highest Degree Completed: Each consecutive level of higher education represents an increasing degree of specialization. It is postulated that those who have received more specialized formal education abroad, based on the degree level, are less likely to return since their advanced training will be more relevant or attuned to the needs of the foreign country and thus provide them with higher monetary returns in the foreign country 
than in their native country. The level of highest degree is represented by the following set of dummy variables: bachelors, masters and doctorate.

If the highest degree completed by a respondent is from a Turkish institution of higher education, then the individual is part of the "classic brain drain" (HD_TUR). On the other hand, if the highest degree completed is from an educational institution outside Turkey, then the respondent is part of the phenomenon of "student non-return" (HD_FOR).

Language Facility / Skill: Language skills may also be an important part of adjusting to life abroad. The greater the command of a foreign language, the easier it is to make the transition to a foreign culture. Language acquisition is also related to the age of the respondent, which suggests that those who go abroad at an earlier age will generally have better command of the foreign language in question. As mentioned before, foreign language instruction in the home country should also increase language skills and prepare students for foreign study or work experience. To account for early exposure to a foreign language, language of instruction in high school for science and social science classes are included as dummy variables in the model (HSsci_TUR and HSsoc_TUR). The expectation is that those who have received foreign language instruction in high school will adjust more easily to a foreign culture (since it will be less foreign to them) and exhibit less intense return intentions than those who complete their high school education in Turkish language schools.

\section{Determinants of Return Intentions}

Tables B.1 and B.2 in Appendix B provide summary statistics and descriptions of the variables used in the final model for each of the targeted groups. The final models were chosen on the basis of goodness-of-fit statistics: mainly the AIC and McFadden's adjusted R ${ }^{2}$. In comparing nested models, the likelihood ratio test was also used. In general, these three statistics give very similar results. The final model for professionals has 59 regressors, many of which are qualitative or dummy variables, as well as interaction variables; while the final 
model for students has 48 regressors. Estimates of the coefficients and the associated marginal effects are provided in Table B.3 for professionals and Table B.4 for students. The marginal effects of various factors on the "non-return" decision are discussed under separate headings below, for Turkish professionals (part A) and Turkish students (part B). The analyses in this section refer to Table 1, Table 2, and Table 3, which give the marginal effects of various discrete and continuous variables.

\section{A. Turkish Professionals}

Gender Effects: There are gender differences in the estimated probabilities of return intentions. Positive, statistically significant coefficients on the dummy variable, female, indicates that female respondents have a higher probability of indicating an intention of "nonreturn". The marginal effects were computed by holding all other explanatory variables at their means and accounting for gender interaction effects (e.g., setting femalexpullK to zero for males and to $1 \mathrm{x}($ mean of pullK) for females). The gender differences in the marginal effects show a clear tendency for females to indicate plans to remain abroad compared to males. The probability of returning to Turkey being unlikely is 0.10 points higher for female respondents, and the probability of definitely returning $(y=1$ or 2$)$ decreases by 0.07 . This may be because educational and migration opportunities for women are more limited, which makes the migration of females a more selective process (e.g., as evidenced by the higher socio-economic background of females in the survey as measured by parental education levels). Another important factor may be the greater freedom of lifestyle that some of them may enjoy while abroad.

Cohort Effects: The age and agesq variables are statistically significant at the $1 \%$ significance level for the ordered probit model when the stay duration and work experience variables are excluded. A positive sign on the age coefficient indicates a higher intensity in non-return intentions for older respondents. This may be a reflection of the possibility that 
older respondents have spent more time abroad than younger respondents and are more firmly established in their overseas careers and/or have become more accustomed to the lifestyle abroad. As such, the "age" variable may be echoing the effects of the "stay duration" variable. Older individuals also tend to be less mobile than younger individuals, and therefore may exhibit a greater tendency ("inertia") to stay in their current place of residence. A negative sign on agesq means that the tendency for individuals to "not return" increases with age at a diminishing rate. When stay duration, years of work experience and possible interaction effects (e.g., AGExSTAYDUR and AGESQxSTAYDUR) are controlled for, the coefficients become marginally statistically insignificant.

Effects of Stay Duration and Work Experience: The probability of returning to Turkey is expected to decrease as stay duration increases, holding everything else constant (including age, work experience, lifestyle preference). Stay duration may be thought of as reflecting "inertial effects": returning becomes more difficult after individuals become accustomed to living conditions abroad. Increases in the length of stay duration may also speed up the acculturation process and shift personal lifestyle preferences toward the culture of the host country. Another important effect of stay duration is that "psychic" or adjustment costs associated with the initial move to a foreign country diminish as the length of stay increases.

Figures 1 and 2 show the effects of stay duration on return intentions holding age constant at 35 years, which is close to the average age for the sample. The marginal effects for the extreme categories (DRP and DNR) are small and lie close to the origin as illustrated in Figure 1, although definite return plans show a decrease in probability with stay duration, while the probability of definitely not returning shows an increase. The overall trend is an increase in the probability of not returning and a decrease in the probability of returning as stay duration increases, which is as expected. 
The number of years of work experience in the host country serves as a proxy for the amount of learning-by-doing accumulated in the host country. Figure 3 presents the effect of different amounts of work experience on return intentions. The same qualitative results apply as for the stay duration variable, except that increases in work experience appear to have a stronger negative effect on return intentions than do increases in stay duration. The probability of not returning ( $y=4$ or 5 ) increases by 0.07 for the first five years of work experience, and then by 0.09 for the second five years, and finally by 0.10 for the next five years after that. By comparison, the same figures for stay duration are $0.03,0.04$ and 0.05 respectively. The negative impact of foreign work experience on return intentions provides empirical support for Wong's learning-by-doing model of brain drain.

Whether a respondent has had any work experience in Turkey also appears to be an important determinant of current return intentions, in addition to the amount of work experience obtained in the host country. When a respondent has no full-time job experience in Turkey (NWexpTUR=1), the probability of not returning $(y=4$ or 5$)$ increases by 0.08 , and is slightly higher for females.

Previous examination of the data using correspondence analysis (Güngör, 2003) suggested the possibility that respondents who returned to Turkey to work after obtaining foreign degrees are less likely to return a second time. The dummy variable FFTJ_TUR takes on a value of 1 for respondents completing their highest degree abroad if their first full-time job (FFTJ) after completing their studies is located in Turkey. The probability of not returning ( $y=4$ or 5 ) increases by 0.18 , while the more positive return intention categories-“definitely return, no plans" (DRNP: y =2) and "return probable" $(\mathrm{RP}: \mathrm{y}=3)$-decrease in total by about the same amount. The probability of choosing the "definitely return, no plans" category decreases by 0.10 for male respondents compared to a decline of 0.07 for females, and the 
probability of "probably returning" (RP) decreases by 0.11 for female respondents versus a decline of 0.07 for males.

These results (e.g., the negative impact of work experience in Turkey for respondents with foreign degrees and the phenomenon of student non-return) have important implications for the "brain circulation" hypothesis, which is pervasive in the current literature on the impact of migratory flows. It appears that respondents who start their work life abroad after completing their overseas studies are less likely to have strong return intentions, and respondents with foreign degrees who start their work life in Turkey are less likely to have plans for returning to Turkey again ${ }^{\dagger}$. Those who make contributions to Turkey during their stay abroad are also more likely to indicate they will return. This is included in the model as the dummy variable contr, which takes on a value of 1 when respondents have contributed either by making donations, taking part in lobbying activities or by participating in activities such as attending conferences in Turkey. The effect of this on the likelihood of returning is substantial: the probability of definitely returning increases by 0.09 . This suggests perhaps that those who are already likely to return are also those contributing the most to Turkey through various activities.

Effect of Initial Intentions: Both the "return" and "undecided" variables are negative and significant at the $1 \%$ significant level. The probability of definitely returning $(y=1,2)$ increases by 0.22 for respondents with an initial intention to return compared to those with an initial return intention of staying abroad. The increase in the probability of definitely returning is lower $(0.10)$ when the comparison group is those who are initially unsure about returning.

\footnotetext{
${ }^{\dagger}$ Toward the end of the survey questionnaire respondents were asked about the frequency of their visits to Turkey for various purposes, including for educational and work endeavours. Unfortunately, this part of the survey had a low response rate and could not be used to determine the degree to which productive brain circulation is occurring on behalf of Turkey.
} 
The probability of being unlikely to return is quite high (0.63) for those whose initial intention is to stay in the host country. The probabilities of definitely not returning and of return being unlikely increases by 0.09 and 0.40 respectively, when respondents have initial "stay" intentions compared to those with initial return intentions. These figures suggest that the initial or prior intentions of individuals tend to shape their current intentions about whether to return to Turkey or not. This tendency, however, appears to be strongest for those with initial plans to remain abroad. These results may be reflecting the "self-fulfilling" tendency of prior intentions and expectations: e.g., those who start out more determined from the outset to make a career or succeed abroad will try harder to make this come true; they may also tend to try to protect themselves psychologically from setbacks or initial adjustment problems, and exhibit greater tolerance when they occur.

Effect of Family Support and Marriage to Foreign Spouse: Respondents were asked about the degree of support (encouragement) that they received from their families (parents, wife, and children) in the initial decision to work or study abroad and in the decision to settle overseas permanently. Maximum likelihood testing procedures were performed to determine whether the ordered family support categories could be treated as interval ${ }^{\ddagger}$. On the basis of the LR test results for the ordered probit model $^{\S}$, fam_supl and fam_sup2 were included as interval variables.

\footnotetext{
* To illustrate: in performing the LR test, the model containing the ordinal variable fam_supl is compared to the model that includes both fam_supl and all but two of the categories of fam_supl. If the restricted model leads to a loss in information, then the ordinal variable cannot be treated as an interval variable (see Long and Freese, 2001: 268-9).

${ }^{\S}$ Test results: fam_supl (ordered probit model): LR $\chi^{2}(2)=5.16$, Prob $>\chi^{2}=0.0757$; fam_sup2 (ordered probit model): $\operatorname{LR} \chi^{2}(4)=5.48$, Prob $>\chi^{2}=0.2414$;
} 
Family support for the initial decision (fam_supl) is negative and significant $(\alpha=0.01)$. This means that the probability of returning increases when there is support for the initial decision to go abroad. In the analysis of the previous chapter, it is clear that there is strong family support the initial decision to acquire overseas study or work experience for a majority of respondents. This variable may be indicative of the strength of ties to family in Turkey, which offers a possible explanation of the negative sign on the fam_supl coefficient and higher probability of return.

The second "family support" variable is a measure of how much encouragement the respondent believes that she/he would receive from her/his family for the decision to settle abroad permanently. The interpretation of the positive and statistically significant coefficient ( $\alpha=0.01)$ in the ordered probit model for the fam_sup2 variable is more clear-cut. Respondents with greater family encouragement in the decision to settle abroad permanently have a greater probability of not returning to Turkey. This outcome appears to validate the importance of family encouragement in the decision to migrate, especially for individuals coming from a traditional, family-oriented society such as Turkey. (This could be compared with other country studies that contain "family" variables).

Another important consideration is marriage to a foreign spouse, which is given by the dummy variable spousenat. The sign of the coefficient on spousenat is negative and statistically significant at the $1 \%$ significance level, indicating a lower intention of returning. Family support for permanent settlement and marriage to a foreign spouse decrease the probability of definitely returning by 0.037 and 0.085 respectively. Initial family support for overseas study or work, on the other hand, tends to increase definite return intentions by 0.04 . As expected, marriage to a foreign spouse has a very large positive effect $(0.14)$ on the probability of "being unlikely to return", which is much larger than the effect of family support for settlement abroad (0.04). 
Effect of Parental Education: Differences in the social background of respondents, as reflected in the educational attainment of their parents, are found to be statistically insignificant in determining current return intentions. "High school" is used as the reference educational attainment category for each parent. No significant relationships were found when the other categories of educational attainment are used as the reference. As a result, parental education levels are not included in the final estimation model. While parental education levels are not important in determining the likelihood of return of respondents, it is apparent that the socioeconomic background of individuals is an important determinant of who leaves Turkey for study and work opportunities in other countries.

Effects of the Initial Reasons for Going: Since initial return intentions appear to be important in determining current return intentions, the initial reasons for going overseas may also provide important information about who is planning to return and who is not. Only six of the possible twelve reasons presented to the respondents are found to have statistical significance. They are the ones included in the final model. Some of these factors become significant only when their interactions with certain variables such as age, female and academic are controlled for.

The results from the estimated ordered probit model indicate that respondents are more likely to return if their initial reason for going was any of the following: having a job requirement in Turkey (whygo_C), prestige of overseas study (whygo_G), or to join spouse (whygo_I). The first two are statistically significant at the $10 \%$ and the last at the $1 \%$ significance level. A positive, significant $(\alpha=0.10)$ coefficient for the interaction term between female and whygo_I (FxWHYGOI) ${ }^{* *}$ and between female and whygo_C

\footnotetext{
*** The in-sample bivariate association between return intentions and whygo_C as measured by the chi-square statistic $\chi^{2}(4)$ is $1.84(\operatorname{Pr}=0.76)$ for females and $8.68(\operatorname{Pr}=0.07)$, even though a greater percentage of female respondents have indicated that their reason for going abroad is to be with their spouses ( $23.1 \%$ versus $8.2 \%$ ).
} 


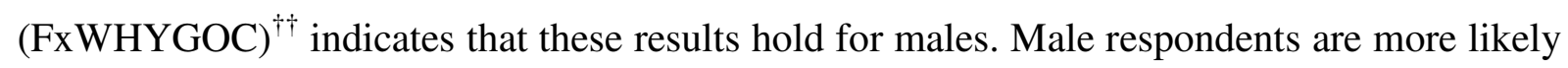
to return if they initially went abroad as a requirement or to be with their spouses. The result for whygo_G (the prestige of overseas study), on the other hand, is moderated by age (through a positive and significant coefficient of the term AGExWHYGOG at the $10 \%$ significance level) and strengthened if the respondent is working in academia (through a negative and significant coefficient of the term ACADxWHYGOG at the 5\% significance level).

As expected, respondents who left Turkey because of lifestyle preferences (whygo_H) or due to political factors (whygo_K) are not likely to indicate strong return plans. The coefficients of these variables are positive and statistically significant at the $5 \%$ and $10 \%$ significance levels respectively. Respondents who left because they found facilities and equipment for doing research in Turkey to be inadequate (whygo_F) are also less likely to be returning (significant at $1 \%$ ).

Lifestyle preference has the greatest negative marginal effect on return intentions, followed by getting away from the political environment and insufficient facilities for conducting research in Turkey. The probability of not returning ( $y=4$ or 5 ) increases by 0.07 for those who have indicated lifestyle preference to be their reason for going abroad, compared to 0.05 for political reasons and 0.03 for insufficient facilities. Respondents who indicated they went abroad to be with their spouse have the highest return intentions: the probability of choosing one of the "definitely return" categories increases by 0.096

\footnotetext{
${ }^{\dagger \dagger}$ The percentage of females in the sample whose initial reason for going abroad was to fulfil a job requirement in Turkey is approximately the same as that for males $(21.7 \%$ versus $22.6 \%)$. Interestingly, the chi-square statistic between return intentions and whygo_C is significant only for males $\left(\chi^{2}(4)=41.57, \operatorname{Pr}=0.00\right)$, and there is a clear tendency (based on an examination of table percentages) for males who chose whygo_C as their reason for going abroad to have stronger return inclination than those who did not.
} 
(0.0054+0.0905), compared to 0.024 for those who went because of a job requirement in Turkey and 0.017 for those who went abroad to take advantage of study opportunities.

Effect of Work, Social and Standard of Living Assessment: Respondents were also asked to assess in general terms their personal work environment (e.g., job satisfaction), the social aspects of life (e.g., friendships, social relations) and standard of living in their current country of residence versus that in Turkey on a 5-point scale ranging from "much worse" to "much better". Work and standard of living assessments (work_assess and SOL_assess) are skewed toward the "better" or "much better" categories. These two variables are positively associated with lifestyle preferences. The distribution of the social assessment variable appears not to be as slanted toward extreme points, although it is tilted toward the "worse" categories. The work_assess variable was not statistically significant and was therefore excluded from the model ${ }^{\ddagger \ddagger}$. The coefficients of social_assess and $S O L \_a s s e s s^{\S \S}$ are positive and statistically significant at the 5\% and $1 \%$ significance levels respectively, indicating a decrease in return intentions when more positive assessments are made about conditions abroad compared to Turkey.

It is clear that positive assessments of living conditions abroad lead to greater decreases in the probability of indicating return intentions than do positive assessment about social conditions abroad. Figures 4 and 5 give the cumulative probabilities associated with each value (1 to 5) that the social_assess and SOL_assess variables take on. Areas toward the bottom represent more definite plans and areas at the top represent more definite non-return

\footnotetext{
Wald test of significance: $\chi^{2}(1)=0.12$, Prob $>\chi^{2}=0.7321$.

$\S \S$ The likelihood ratio test results for whether the ordinal variables can be treated as interval are as follows: social_assess: $\operatorname{LR} \chi^{2}(4)=2.95$, Prob $>\chi^{2}=0.5663 ;$ SOL_assess: $\operatorname{LR} \chi^{2}(4)=11.58$, Prob $>\chi^{2}=0.0207$.

The likelihood ratio test results indicate that social_assess can be used at the interval level, but treating SOL_assess as an interval variable leads to loss of information. Despite this, both variables were included as interval variables in order to keep the model simple. This did not lead to a change in the qualitative results.
} 
intentions. These diagrams also show that standard of living assessments have a greater impact on return intentions than assessments made about social environment.

Level and Location of Highest Degree: It is expected that higher levels of formal education received abroad (e.g., PhD level education), corresponding to a greater degree of country or institution-specific specialization, will result in a lower tendency for returning to Turkey. While the highest degree held by the respondent has no significant effect on the return intentions of respondents, where the highest degree is received is statistically significant at the $1 \%$ significance level. Those who have received their highest degree from a Turkish university are more likely to indicate they will return than those whose highest degree is a foreign degree. Therefore, higher education received abroad, regardless of the level, is important in the decision to return or stay ${ }^{* * *}$. This also means that student non-return is a potentially more serious problem for Turkey.

Effect of the Field of Study: Capital Intensive versus Non-Capital Intensive Fields: According to Chen and $\mathrm{Su}$ (1995), students in capital-intensive fields (where a complementary relationship exists between the education received and the physical and social capital stock of the host country) will be less likely to return than students in non capitalintensive fields (such as law, sociology and the like). To test this, the highest degree fields were arranged into three groups: HDnewl (architecture, economics and administrative sciences); HDnew2 (education, language, sociology, art) and HDnew3 (engineering, mathematics, science and medicine). The reference category is HDnew2. In the ordered probit analysis, the coefficients on HDnewl and HDnew3 are both positive and statistically significant at the $1 \%$ significance level, indicating that those in the "hard sciences" or more

\footnotetext{
**** The analysis was done with the dummies HD_TUR (highest degree is from Turkey), FHD_BS (highest degree is a foreign bachelors degree), FHD_MS (highest degree is a foreign master's degree) and FHD_PHD (highest degree is a foreign doctoral degree).
} 
capital intensive fields (HDnew3), as defined by Chen and $\mathrm{Su}$, are more likely to stay abroad compared to those in education, language, and so on. However, the least likely to return are those who hold their highest degrees in architecture, economics or administrative sciences. Economic instability and the crisis environment in Turkey, which has had important repercussions in the banking and finance sectors, offers an explanation for this.

On-the-Job Training and Formal Training: One of the main arguments set forth by Chen and Su (1995) to explain the phenomenon of student non-return is on-the-job training. Training received on the job abroad after completing overseas studies is expected to instill skills that are given a higher premium in the country in which they are received. This wage differential, in turn, is supposed to favor the host country and keep foreign workers abroad. To test on-the-job training as a cause of brain drain directly, respondents were asked whether they have received informal on-the-job training at their current overseas jobs. Nearly $60 \%$ of respondents have received some on-the-job training, and for $10 \%$, this training is specific to the organization and cannot be easily transferred to other organizations.

The following dummy variables were constructed: OTJT1 (did not receive on-the-job training), OTJT2 (general), OTJT3 (specific to industry), and OTJT4 (specific to organization). The signs on these variables were as expected. With "no on-the-job training" as the reference category, the coefficients of the "general", "specific to industry" and "specific to organization" were positive but not statistically significant. This indicates that on-the-job training does not have explanatory power for differences in return intentions. On the other hand, formal training specific to the organization (represented by FTr4) is positive and statistically significant at the $10 \%$ level indicating that respondents who have gone through formal specialized training are less likely to return. The probability of not returning to Turkey ( $y=4$ or 5 ) increases by 0.14 while the probability of definitely returning ( $y=1$ or 2 ) falls by 
0.08. Firm-specific training as a cause of brain drain is limited to a very small proportion of participants in the sample $(3.8 \%)$.

$\mathrm{R} \& \mathrm{D}$ activities are given a greater premium in advanced countries compared to the developing countries. Those engaged in $R \& D$ are therefore expected to be less willing to return. In the sample, about $40 \%$ of those engaged in research and development activities are academicians $(166 / 421 * 100)$. The R\&D dummy variable was not significant at any conventional significance level. This is not an expected result since The problem here may be how respondents interpreted the different job activities ${ }^{\dagger \dagger \dagger}$.

Academic vs. Non-Academic Professions: In the analysis, "academic" refers to individuals who are teaching and/or doing research at a 4-year university or at research centers and medical schools affiliated with a 4-year university. Academicians make up 30\% of the overseas labor force sample. A dummy variable, academic2, is used ( 1 for academic, 0 for non-academic) to determine whether the return intentions of the academicians in the sample differ from the non-academic labor force. This variable is not found to be statistically significant, although it is an important modifier or interaction variable in the analysis of push and pull factors.

Effects of Various Push and Pull Factors: Income or wage differentials are cited as among the most important reasons for the brain drain. Many elaborate models of the brain drain found in the literature are based on explaining how this differential occurs. We use a relatively simple test of whether income differentials are important. To determine whether income differentials are important, we include a dummy variable that takes on the value 1 when a respondent indicates that a higher salary or wage is a "very important" or "important"

\footnotetext{
tit The respondents were also asked if they had any patented inventions. A dummy variable 'patent' was constructed $(1=$ 'has patent'; $0=$ 'does not have patent') to determine whether return intentions for individuals with patents differed from those without. The coefficient for this variable was not statistically significant.
} 
reason for not returning or postponing returning to Turkey on a 5-point Likert scale. The disadvantage of this construct is that it is a subjective measure. The income variable was found to be statistically significant and therefore excluded from the final model.

Of the twelve "push" factors presented to participants, only four were found to be statistically significant: pushC (limited job opportunity in specialty), pushD (no opportunity for advanced training), pushF (lack of financial resources for business) and pushK (economic instability and uncertainty). Having limited job opportunities in specialization carries greater significance for those in academia or research-oriented institutions (given by dummy variable academic2). While the coefficient of pushC is not statistically significant, the coefficient of the interaction between pushC with academic2 (ACADxpushC) is positive and significant at the $5 \%$ significance level. A significant interaction effect (at the $1 \%$ significance level) was found between having little or no opportunities for advanced training (pushD) and the age of participants (AGExpushD). Respondents who indicated that the lack of financial resources and opportunities for starting a business in Turkey (pushF) was an important push factor for them are more likely to be returning. The coefficient on pushF is negative and significant at the $10 \%$ significance level. Economic instability and uncertainty, on the other hand, appears to have a strong negative effect on return intentions (statistically significant at $1 \%$ ). The marginal effects on each of the significant push factors are presented in Table 3:

It is clear that the greatest negative effect on return intentions is due to economic instability and uncertainty: the probability of not returning ( $y=4$ or 5$)$ increases by 0.12 for those indicating that pushK was a "very important" or "important" push factor (which accounts for $85 \%$ of respondents in the sample). For those working in academic or researchoriented organizations, having no job opportunities in their specialization in Turkey increases the probability of not returning by 0.04 . Having no advanced training opportunities increases the probability of non-return by 0.03 for the average respondent. However, this negative 
impact of pushD on return intentions is greater for older respondents (see Figure 6). On the other hand, the probability of definitely returning increases by 0.03 for those indicating that the lack of business opportunities in Turkey is an important push factor. This may be reflecting the fact that the percentage of non-academic respondents who indicated pushF is an important factor is much greater than that of academics (33\% versus $22 \%$ ), who have a much higher non-return probability.

The number of significant pull factors is greater compared to the push factors. Eight of the twelve pull factors presented to participants are found to be statistically significant. Since respondents in the target group are residing outside Turkey, it is natural that factors in their immediate environment will have a greater impact on their current return intentions. Table 3 gives the marginal effects of the significant pull factors. The greatest negative impact on the probability of returning is from family considerations (pullI and pullJ), but there are gender differences. Spouse's job or preference appears to play a greater role in the stay decision of males. Greater opportunities for developing specialty (pullE), a more satisfying social and cultural life (pullG), proximity to research centers (pullH) and a more organized, ordered environment (pullF) follow. The other two pull factors - the need to finish or complete an overseas project (pullK) and other reasons (pullL) for male respondents—are associated with positive return intentions. For males, the effect of "other" factors is mainly that of wanting to return to complete military service in Turkey.

Effect of Difficulties Faced Abroad and Adjustment Factors: The main difficulty with life abroad that was statistically significant $(\alpha=0.05)$ in the empirical analysis is that of missing one's family in Turkey (difabrdA). The probability of returning ( $y=1$ or 2$)$ increases by 0.05 for those who indicate that missing family is one of the difficulties they have faces while abroad. "Missing family" was an important difficulty for a great proportion of respondents in the sample (83\%). Previous experience and involvement in a Turkish student 
association also have a similar, but slightly greater impact on return intentions. The greater return intentions associated with these adjustment factors may be due to the fact that respondents who indicate they have had difficulties abroad also have to adjust compared to those who indicate they had no difficulties and therefore did not need to adjust.

Effect of Language of Instruction in High School: The effect of foreign language high school instruction was looked at with the dummy variable HSsciTUR, which takes on a value of 1 when language instruction for science courses is Turkish. However, this variable is positively associated with difficulties faced abroad (difabrdA) and previous experience as an adjustment factor $\left(\operatorname{adj} \_A\right)$, as well as other factors. As a result it is statistically insignificant in the model. In a model with only gender, initial intentions and stay duration, HSciTUR becomes statistically significant at the $5 \%$ level.

Effect of Last Impressions: Return intentions may be shaped by the last impression from the latest trip to Turkey. In this section we consider the effect of the last visit made to Turkey on the return intentions of participants. A visit to Turkey made after a long period of time abroad may radically change an individual's perceptions about conditions in Turkey, either for the better or for the worse. Whatever the case, these personal observations lead to changes in the probability of returning. The probability of returning ( $y=1$ or 2$)$ decreases by about 0.04 for those who were negatively effected by their last trip to Turkey, and increases by 0.22 for those who were left with more positive impressions. From this, it appears that positive impressions appear to have a greater impact on the probability of returning.

The effect of the September 11, 2001 terrorist attacks in New York is also considered. The effect, in general, is to increase return intentions (sept11_inc is negative and statistically significant at the $5 \%$ significance level. The probability of returning $(\mathrm{y}=1$ or 2$)$ increases by 0.07. For a small minority of respondents, Sept.11 had the opposite effect on return intentions (sept11_dec is not statistically significant and is therefore excluded from the final model). 


\section{B. Return Intentions of Turkish Students}

In this section, the focus is on the return intentions of Turkish students studying at higher education institutions in different parts of the world. Much of the analyses presented in the previous section are in agreement with that of students; thus, a more brief treatment of the results will follow. The same estimation strategies and methodologies apply for the investigation of the return intentions of Turkish students.

Gender and Age Effects: Unlike the results for professionals, gender and age do not appear to be significant in explaining differences in return intentions for the overseas Turkish student population. The coefficients on the "female", "age", and "agesq" variables are not statistically significant at any of the conventional significance levels. This result continues to hold when the stay duration variable is excluded.

Stay Duration: The stay duration variable is positive and statistically significant at the $1 \%$ significance level. As the length of stay in the host country increases, the tendency to "stay abroad" also increases. This is as expected, since time helps overcome adjustment problems, if they exist. As time passes, ties to Turkey may weaken while ties to the country of study may strengthen. Figure 7 gives the marginal effects of different stay durations for each return intention category.

Effect of Initial Intentions: A little more than half the of the students sampled intended to return prior to leaving Turkey, while one out of every ten student intended not to return and the remainder were unsure about returning. The coefficients on init_stay and init_unsure are positive and statistically significant $(\alpha=0.01)$, which indicates that those who have indicated that they will "stay" in the current country or are "unsure" about returning are more likely to indicate that their current intention is to "not return". The probability of not returning $(y=5$, 6) increases by 0.32 when initial intention changes from "stay" to "unsure" and by 0.38 when 
the change is from "stay" to "return". These large marginal effects suggest that initial determination becomes an important factor in shaping current intentions for Turkish students.

Effect of Family Support: The student sample was also asked the degree that they felt that their families supported them in the initial decision to study abroad and whether they would support them in the decision to settle abroad permanently. For the initial decision to study abroad, three-quarters of the student sample indicated that their families were very supportive. In general, this initial support does not have any statistical significance with respect to the current intention to return. Compared to the initial decision to study abroad, family encouragement to settle abroad is considerably less, although it is still high (53\% of the sample).

Initially, dummy variables for each category were included in the model as regressors. Since the first three categories "actively discourage", "not very supportive" and "not sure" are not statistically different from each other, they are combined into the broader category FAMSUP2_NS: "not supportive", which is used as the reference category. The same is done for the "somewhat supportive" and "most likely supportive" categories since they are also not statistically different from each other. They are combined into a new "somewhat supportive" category: FAMSUP2_SS. Only the "definitely not support" category is not changed (FAMSUP2_DS). The signs on the FAMSUP2_SS and FAMSUP2_DS dummy variables are positive and statistically significant at the $5 \%$ and $1 \%$ significance level respectively. Greater family encouragement to settle abroad results in a greater tendency to indicate non-return intentions, and vice versa. Compared to respondents whose families are not supportive (NS), the likelihood of not returning $(y=5$ or 6$)$ increases by 0.04 for those whose families are somewhat supportive (SS), and by 0.08 for those whose families are definitely supportive (DS). 
Effects of Parents' Education: Parents' educational levels were included in the ordered probit model as possible socioeconomic background indicators for the respondents. A dummy variable was constructed for each level of education and different levels of education were used as reference to determine whether any significant differences existed in the return intentions of students with different family backgrounds. None of the parents' education level dummies were statistically significant except for the master's level for fathers' educational attainment $(\alpha=0.05)$. Again, as for the professionals sample, there was no a priori reason to believe that we would find significant effects for these two social background variables. The respondents come from highly educated backgrounds. Three-quarters of female students and two-thirds of male students have fathers who possess a bachelor's or higher degree. These are the same percentages as for the professionals sample. Mothers' educational attainments, on the other hand, are slightly higher for the student sample $(51 \%$ vs. $47 \%$ for female respondents and $41 \%$ vs. $34 \%$ for male respondents).

Effect of Academic Conditions: Students were asked to compare their academic environments in their current country of study to that in Turkey. The great majority (close to 90\%) of students indicated that academic conditions were either "better" or "much better". A dummy variable was constructed for each assessment category, and only the "much worse" category appeared statistically significant at the 5\% significance level with reference to the other categories. However, only two individuals chose the "much worse" category, and when this category was chosen as the reference, none of the other categories were statistically significant. This indicates that the academic assessment variables do not have any explanatory power and may be excluded from the model.

Effect of Social Conditions: In the previous section, social environment was found to be important in explaining differences in return intentions for professionals. Hence, it is expected that this will be true for the student sample as well. A third of respondents have indicated that 
their current social environment is "neither better nor worse" than it was in Turkey, and a significant number (43\%) indicate that it is "worse" or "much worse".

The above categories above were reduced to three (not counting the "don't know" category) by combining the "worse" and "much worse" categories, and the "better" and "much better" categories. With "much worse" as the reference category, both the "neither better nor worse" and "better" categories are positive and statistically significant at the $1 \%$ significance level. When the reference category is "much better", both the "neither better nor worse" and "worse" dummy variables are negative and statistically significant, at the the 5\% and $1 \%$ significance levels respectively. As before, the social environment is found to be an important determinant of current return intentions. Those who are less satisfied with their social conditions abroad are more likely to indicate that they will return.

Standard of Living Assessment: Students were also asked to assess their standard of living using the same scale as above. The distribution of responses is tilted toward the "much better" end of the scale. Since the coefficients of the "much better" and "better" dummy variables are not statistically different from each other, they are combined. Similarly, the first four categories can also be combined into a single category because they are statistically insignificant with respect to each other. This latter variable is used as the reference. The coefficient of the "standard of living is better" variable $\left(S O L_{-} B\right)$ is positive and statistically significant at the 5\% significance level. Not surprisingly, once again, students who assess their standard of living abroad as being better or much better than in Turkey show greater intention to stay (not return).

Turkish Student Association Membership: More than half the students responding to the survey belong to a Turkish student association or society (TSA) at their institution of study. Membership in these cultural associations turns out to be an important determinant of return intentions. The coefficient of the dummy variable for membership (TSA_member) is negative 
and statistically significant at the $1 \%$ significance level, indicating that students who are members of TSAs are more likely to have return intentions. This probably reflects a preference on the part of TSA members to be with fellow nationals compared to non-members and is possibly an indication of stronger "cultural ties" to Turkey.

If a student is not a member of a TSA, this is because of personal choice or because no TSA exists. Not being a member by choice and not being a member because no TSA exists were not statistically different from each other and were, therefore, used combined as the reference category.

Effects of the Field of Study: In the previous section on the return intentions of Turkish professionals, the Chen and Su (1995) hypothesis that on-the-job training causes "brain drain" was tested. Chen and $\mathrm{Su}$ used a dummy for capital-dependent disciplines, which they determined to be medicine, engineering and business. In their econometric analysis, they found that capital dependent disciplines suffered more from brain drain than non-capital dependent disciplines. The same dummy variable for capital-dependent disciplines is constructed in our analysis to see if the same result will hold for the sample of Turkish students currently studying abroad. This dummy variable turned out to be statistically insignificant ${ }^{\dagger+t}$.

Effect of the Initial Reasons for Going: The initial reasons for pursuing overseas studies also determine who is more likely to return immediately after completing their studies. The greatest positive marginal effect on the probability of returning immediately after finishing studies is when the main reason why respondents have gone abroad is to be with their spouse

\footnotetext{
*\$ A dummy variable for each discipline, in turn, was also used in the model to determine whether certain fields of study are more prone to brain drain than other. The disciplines are "architecture", "economic and administrative sciences", "engineering and technical sciences", "education sciences", "language and literature", "math and natural science", "medicine", "social sciences", and "arts". None were found to be statistically significant from each other except for econ./admin. and engin./tech. with education at the 5\% significance level.
} 
or families: the probability of returning immediately increases by 0.11 . When there is compulsory service or job requirement—such as when higher education institutions in Turkey require foreign degrees before they grant tenure positions-the probability of returning immediately increases by 0.03 . This is one of the important "push" factors that cause many who are contemplating academic careers in Turkey to go abroad to get foreign higher level degrees. While the probability of return increases when respondents have left because of a job requirement, many do not have immediate return plans. Given that stay duration affects the probability of returning negatively, many are not expected to return, especially if they find good positions abroad.

The other reasons for pursuing foreign studies abroad that have a positive effect on return intentions are when respondents go abroad in order to improve their language skills or if they want to take advantage of the prestige and opportunities associated with overseas studies. International diplomas are an important signal to employees in Turkey and those with foreign degrees are more likely to get accepted or promoted. Foreign degrees, therefore, increase the employability of individuals in Turkey, which is a factor that has a positive effect on return intentions. Language skills are also given a premium by Turkish employers.

When respondents go abroad to get away from the political environment, or due to lifestyle preferences, or because they find the facilities and equipment in Turkey to do research insufficient, they are very unlikely to return. The probability of not returning $(y=5$ or 6) increases by 0.11 for those who left due to political reasons, by 0.05 for those who left due to a lifestyle preference, and 0.02 for those who left due to insufficient facilities for research. If students choose their current institution of study because of the job opportunities they are given or to be in the same location as their spouse, the probability of non-return increases by 0.06 and 0.11 , respectively. Interestingly, the effect of family considerations can have quite different effects on the intention of returning. 
Effect of Difficulties Faced Abroad and Adjustment Factors: As in the professionals case, the probability of definitely returning increases when the psychic costs associated with being in a foreign country are high. When employment prospects abroad are dim, the probability of returning immediately after completing studies increases by 0.03 . When respondents indicate that they had to adjust to their environment (which is implied when they choose certain factors such as previous experience as important in adjusting), the probability of returning also increases. While Turkish friends at current institution of study may be important for easing adjustment, those who indicated that this was an important adjustment factor for them are more likely to be returning. This may also be an indication of strong ties to Turkish community and to Turkey for some.

Effects of Compulsory Academic Service and Plans for Academic Career: As expected, students who finance their studies with national scholarships that have a compulsory academic service requirement are more likely to be returning immediately after completing their studies. The probability of returning immediately is 0.05 for those without a compulsory academic service requirement, and 0.17 for those who have this requirement. While the marginal effect between these two groups appears to be large $(0.12)$, what is worrisome is that the probability of returning immediately is not higher. Non-returning students are an indication that the scholarships are not as successful as they can be. Those who are planning an academic career are also more likely to have return intentions. Despite the difficulties within the higher education system in Turkey, universities provide greater opportunities for employment compared to other sectors, especially in the recent economic crisis environment where many university graduates face the prospect of being unemployed.

Effects of Various Push and Pull Factors: Two push factors were important in determining return intentions for students: being away from research centers / recent advances and finding the cultural or social life to be less than satisfying in Turkey. The negative impact 
of finding the cultural and social life in Turkey less satisfying is slightly less for those contemplating academic careers (0.07 compared to 0.10$)$. The marginal impact of being away from research centers and recent advances on the probability of not returning is 0.04 .

The pull factors that significantly affect the return intentions of students are a higher income level in the host country (pullA), a more ordered and organized life (pullF), and spouse's preference or job (pullI). The greatest negative impact on return intentions are due to family considerations, followed by income levels and a more ordered lifestyle. The importance of salary levels for students contemplating an academic career is confirmed by the following observation:

From talking with students who decide to stay here rather than go back to Turkey, the primary reason is financial. Very able $\mathrm{PhD}$ graduates who can become excellent faculty in Turkey, most of the time decide on even a mediocre job here (which will not satisfy them in the long run) rather than become a faculty member in Turkey with the current salaries. If Turkey does not improve the living standards of university faculty ... the price paid will be incalculable. Here in US the best go into academia, there it looks like it is the people who either have money or could not find anything else (most of the time).

Effect of Last Impressions: For professionals, the last impression from the latest trip to Turkey has an important impact on return intentions. The same is true for students. The last visit to Turkey changes an individual's perceptions about conditions in Turkey. The probability of returning ( $y=1$ or 2 ) decreases by about 0.04 for those who were negatively effected by their last trip to Turkey, and increases by 0.05 for those who were left with more positive impressions. The effect of the September 11, 2001 terrorist attacks in New York is given by sept11_inc. The effect of Sept. 11 is to increase return intentions. The probability of returning ( $y=1$ or 2 ) increases by 0.04 which is less than that of professionals $(0.07)$.

\section{Concluding Remarks}

In economic explanations of the brain drain, skilled migration is viewed as a response to the wage differentials that exist between the host and source countries. Wage differentials, however, provide only a partial explanation for why skilled migration from developing 
countries to developed countries exists. The ordered probit models estimated in the current study are based on the human capital theory of migration, which predicts that individuals will migrate when the net present value of benefits from migration is positive.

In both the students and professionals groups, the greatest positive impact on the probability of not returning occurs when the initial return intention is to stay compared to those who initially intended to return. Family considerations, not surprisingly, have considerable weight in the mobility decisions of the survey participants, indicating that remaining abroad is not simply a matter of earning a higher salary or enjoying better work conditions. Marriage to a foreign spouse is obviously an important factor in not returning. For others, concern over children's adaptation to the highly competitive education system in Turkey may also dominate the return decision. In both the student and professionals survey groups, family support for the decision to settle abroad is found to be an important factor determining return intentions.

Female respondents appear less inclined to be returning to Turkey than male respondents. In general, the parental education levels of female participants are greater than that of males indicating that they come from a higher socio-economic background. This may be indicative of a more selective migration process working in the case of females. Some female participants have indicated that they enjoy greater freedom in lifestyle choice abroad than they do in Turkey, which may also be an important factor in the non-return decision.

Stay duration, work experience in the host country and specialized training are all found to have significant negative impacts on the return intentions of Turkish professionals. In addition, work experience in Turkey after obtaining a PhD abroad increases the likelihood of not returning. Among the push and pull factors, economic instability has the greatest deterrent effect on return. Female participants and those in academe are also less likely to be returning in the professionals group. The income differential is an important consideration for a 
majority of respondents (e.g., marked by a majority as "very important" or "important") in the two groups. The income differential, however, fails to be a discerning factor in distinguishing between respondents with strong return intentions versus those with weak return intentions in the professionals sample, since a good proportion of respondents consider it to be an important factor.

The results for Turkish students studying abroad suggest that family considerations, lifestyle factors, higher salaries and the political environment are prominent in non-return intentions. On the other hand, the compulsory academic service requirement has a positive effect on return intentions, although many of those who intend to return are not planning to return immediately after completing their studies.

\section{References}

Atkinson, R. and Flint, J. (2001), "Accessing Hidden and Hard-to-Reach Populations: Snowball Research Strategies", Social Research Update, Issue 33, Department of Sociology, University of Surrey, UK, http://www.soc.surrey.ak.uk/sru/SRU33.html

Chen, T.-J. and Su, H.-Y. (1995), "On-the-job Training as a Cause of Brain Drain," Weltwirtschaftliches Archiv, 131(3), 526-41.

Cortés, C. (ed.) (1980), The Latin American Brain Drain to the United States, New York: Arno Press.

Güngör, N. D. (2003), Brain Drain from Turkey: An Empirical Investigation of the Determinants of Skilled Migration and Student Non-Return, unpublished $\mathrm{PhD}$ thesis, Institute of Social Sciences, Middle East Technical University, Ankara.

Goss, E.P. and C. Paul (1986), “Age and Work Experience in the Decision to Migrate," The Journal of Human Resources, 21(3), 397-405.

IIE (2001), Open Doors 2001: Report on International Educational Exchange, Institute of International Education, NY: New York.

Işı̆̆ıçok, Ö. (2002), “Türkiye'de yaşanan son ekonomik krizlerin sosyo-ekonomik sonuçları: Kriz işsizliği ve beyin göçü”, (The socioeconomic results of the last two economic crises in Turkey: Crisis unemployment and brain drain), www.isguc.org/calhay_beyingocu.php

Kao, C. and J. W. Lee (1973) "An Empirical Analysis of China's Brain Drain to the United States," Economic Development and Cultural Change, 21(3), 500-13. 
Kurtuluş, B. (1999) Amerika Birleşik Devletleri’ne Türk Beyin Göçü (Turkish Brain Drain to the United States), İstanbul: Alfa Basım Yayım Dağıtım.

Long, J. S. and J. Freese (2001) Regression Models for Categorical Dependent Variables Using Stata, College Station, TX: Stata Press.

Maddala, G. S. (1983) Limited-Dependent and Qualitative Variables in Econometrics, Econometric Society Monographs, Cambridge: Cambridge University Press.

Niland, J. R. (1970) The Asian Engineering Brain Drain: A Study of International Relocation into the United States from India, China, Korea, Thailand and Japan, D. C. Heath and Company, Lexington, Massachusetts.

NSF (1997) Survey of Doctorate Recipients, Division of Science Resources Studies, National Science Foundation, Arlington, VA.

OECD (1994) Proposed Standard Practice for Surveys of Research and Experimental Development: "Frascati Manual 1993", The Measurement of Scientific and Technological Activities Series, Organization for Economic Co-operation and Development, Paris.

Oğuzkan, T. (1971) Yurt Dışında Çalışan Doktoralı Türkler: Türkiye'den Başka Ülkelere Yüksek Seviyede Eleman Göçü Üzerinde Bir Araştırma (Turks with Doctorate Degrees Working Abroad: An Investigation of the Migration of Highly Skilled Workers from Turkey to Other Countries), Ankara: Orta Doğu Teknik Üniversitesi.

Oğuzkan, T. (1975) “The Turkish Brain Drain: Migration of Tendencies among Doctoral Level Manpower," in R. E. Krane (ed.) Manpower Mobility Across Cultural Boundaries: Social, Economic and Legal Aspects, The Case of Turkey and West Germany, Leiden, Netherlands: E.J. Brill.

Rea, L. M. and R. A. Parker (1997) Designing and Conducting Survey Research: A Comprehensive Guide, Second Edition, San Francisco: Jossey-Bass Publishers.

Stark, O. and D. E. Bloom (1985) "The New Economics of Labor Migration," American Economic Review, Papers and Proceedings, 75(2), 173-178.

Zweig, D. and Changgui, C. (1995) China's Brain Drain to the United States: Views of Overseas Chinese Students and Scholars in the 1990s, China Research Monograph, Institute of East Asian Studies, University of California, Berkeley, CA. 
Table 2

Marginal Effects (Discrete Change), Professionals

\begin{tabular}{|c|c|c|c|c|c|}
\hline Change in Probabilities: & $\begin{array}{l}\text { DRP } \\
\mathrm{y}=1\end{array}$ & $\begin{array}{c}\text { DRNP } \\
\mathrm{y}=2\end{array}$ & $\begin{array}{c}R P \\
y=3\end{array}$ & $\begin{array}{c}\mathrm{RU} \\
\mathrm{y}=4\end{array}$ & $\begin{array}{l}\text { DNR } \\
\mathrm{y}=5\end{array}$ \\
\hline Female $(0 \rightarrow 1)$ & -0.0027 & -0.0646 & -0.0413 & 0.0998 & 0.0088 \\
\hline NWexpTR $(0 \rightarrow 1)$ & -0.0020 & -0.0482 & -0.0280 & 0.0722 & 0.0060 \\
\hline Female $=0$ & -0.0026 & -0.0519 & -0.0210 & 0.0705 & 0.0049 \\
\hline Female $=1$ & -0.0012 & -0.0385 & -0.0436 & 0.0737 & 0.0095 \\
\hline FFTJ_TUR $(0 \rightarrow 1)$ & -0.0031 & -0.0919 & -0.0873 & 0.1630 & 0.0194 \\
\hline Female $=0$ & -0.0039 & -0.1001 & -0.0741 & 0.1620 & 0.0162 \\
\hline Female $=1$ & -0.0017 & -0.0711 & -0.1149 & 0.1581 & 0.0295 \\
\hline Contr $(0 \rightarrow 1)$ & 0.0039 & 0.0881 & 0.0508 & -0.1315 & -0.0112 \\
\hline init_STAY $\rightarrow$ init_UNSURE & 0.0025 & 0.1161 & 0.2436 & -0.2775 & -0.0846 \\
\hline init_UNSURE $\rightarrow$ init_RETURN & 0.0052 & 0.0946 & 0.0292 & -0.1212 & -0.0078 \\
\hline init_STAY $\rightarrow$ init_RETURN & 0.0077 & 0.2107 & 0.2728 & -0.3987 & -0.0924 \\
\hline Spousenat $(0 \rightarrow 1)$ & -0.0030 & -0.0823 & -0.0673 & 0.1383 & 0.0145 \\
\hline whygo_C $(0 \rightarrow 1)$ & 0.0011 & 0.0224 & 0.0100 & -0.0313 & -0.0023 \\
\hline whygo_F $(0 \rightarrow 1)$ & -0.0008 & -0.0183 & -0.0106 & 0.0274 & 0.0023 \\
\hline whygo_G $(0 \rightarrow 1)$ & 0.0005 & 0.0119 & 0.0065 & -0.0175 & -0.0013 \\
\hline whygo_H $(0 \rightarrow 1)$ & -0.0018 & -0.0407 & -0.0228 & 0.0605 & 0.0049 \\
\hline whygo_I $(0 \rightarrow 1)$ & 0.0054 & 0.0905 & 0.0196 & -0.1092 & -0.0064 \\
\hline whygo_K $(0 \rightarrow 1)$ & -0.0014 & -0.0331 & -0.0183 & 0.0489 & 0.0039 \\
\hline HDPHDxTUR $(0 \rightarrow 1)$ & 0.0093 & 0.1320 & 0.0113 & -0.1451 & -0.0075 \\
\hline HDnew2 $\rightarrow$ HDnew 1 & -0.0051 & -0.1193 & -0.0764 & 0.1836 & 0.0172 \\
\hline HDnew2 $\rightarrow$ HDnew3 & -0.0034 & -0.0670 & -0.0240 & 0.0886 & 0.0060 \\
\hline HDnew1 $\rightarrow$ HDnew3 & 0.0017 & 0.0523 & 0.0524 & -0.0950 & -0.0112 \\
\hline $\mathrm{FTr} 4(0 \rightarrow 1)$ & -0.0025 & -0.0726 & -0.0651 & 0.1261 & 0.0139 \\
\hline Acacemic $2(0 \rightarrow 1)$ & -0.0021 & -0.0510 & -0.0329 & 0.0790 & 0.0070 \\
\hline pushC $(0 \rightarrow 1)$ & -0.0005 & -0.0188 & -0.0228 & 0.0371 & 0.0050 \\
\hline $\operatorname{pushD}(0 \rightarrow 1)$ & -0.0006 & -0.0159 & -0.0088 & 0.0234 & 0.0019 \\
\hline pushF $(0 \rightarrow 1)$ & 0.0015 & 0.0318 & 0.0140 & -0.0441 & -0.0032 \\
\hline pushK $(0 \rightarrow 1)$ & -0.0056 & -0.0961 & -0.0228 & 0.1174 & 0.0071 \\
\hline pulle $(0 \rightarrow 1)$ & -0.0033 & -0.0648 & -0.0246 & 0.0867 & 0.0059 \\
\hline pullF $(0 \rightarrow 1)$ & -0.0020 & -0.0399 & -0.0162 & 0.0542 & 0.0038 \\
\hline pullG $(0 \rightarrow 1)$ & -0.0024 & -0.0605 & -0.0390 & 0.0937 & 0.0083 \\
\hline pullH $(0 \rightarrow 1)$ & -0.0017 & -0.0530 & -0.0532 & 0.0965 & 0.0115 \\
\hline pullI $(0 \rightarrow 1)$ & -0.0033 & -0.0786 & -0.0504 & 0.1215 & 0.0109 \\
\hline pullJ $(0 \rightarrow 1)$ & -0.0031 & -0.0716 & -0.0417 & 0.1073 & 0.0090 \\
\hline pullK $(0 \rightarrow 1)$ & 0.0123 & 0.1694 & 0.0159 & -0.1873 & -0.0102 \\
\hline pullL $(0 \rightarrow 1)$ & 0.0106 & 0.1328 & -0.0032 & -0.1341 & -0.0060 \\
\hline difabrdA $(0 \rightarrow 1)$ & 0.0019 & 0.0475 & 0.0312 & -0.0741 & -0.0066 \\
\hline Adj_a $(0 \rightarrow 1)$ & 0.0030 & 0.0640 & 0.0292 & -0.0897 & -0.0066 \\
\hline Adj_c $(0 \rightarrow 1)$ & 0.0036 & 0.0640 & 0.0174 & -0.0800 & -0.0049 \\
\hline Lastvis1 $(0 \rightarrow 1)$ & -0.0015 & -0.0350 & -0.0200 & 0.0522 & 0.0043 \\
\hline Lastvis3 $(0 \rightarrow 1)$ & 0.0175 & 0.2044 & -0.0054 & -0.2065 & -0.0099 \\
\hline Sept11_inc $(0 \rightarrow 1)$ & 0.0037 & 0.0671 & 0.0191 & -0.0847 & -0.0053 \\
\hline
\end{tabular}


Table 3

Marginal Effects (Continuous Variables), Professionals

\begin{tabular}{lccccc}
\hline \hline & DRP & DRNP & RP & RU & DNR \\
Probabilities: & $\mathrm{y}=1$ & $\mathrm{y}=2$ & $\mathrm{y}=3$ & $\mathrm{y}=4$ & $\mathrm{y}=5$ \\
\hline
\end{tabular}

\section{Initial family support}

fam_sup1

$\begin{array}{lccccc}\text { marginal effect } & 0.0019 & 0.0413 & 0.0206 & -0.0593 & -0.0045 \\ \text { Z-value } & (2.21)^{* *} & (2.79)^{* * *} & (2.61)^{* * *} & (-2.82)^{* * *} & (-2.31)^{* *}\end{array}$

Family support for permanent settlement

fam_sup2

$\begin{array}{lccccc}\text { marginal effect } & -0.0016 & -0.0362 & -0.0181 & 0.0520 & 0.0039 \\ \text { z-value } & (-3.11)^{* * * *} & (-5.28)^{* * *} & (-4.25)^{* * *} & (5.43)^{* * *} & (3.49)^{* * *}\end{array}$

Social Assessment social_assess

$\begin{array}{lllll}-0.0011 & -0.0237 & -0.0118 & 0.0340 & 0.0026 \\ (-2.09)^{* *} & (-2.42)^{* *} & (-2.29)^{* *} & (2.42)^{* *} & (2.25)^{* *}\end{array}$

Standard of Living Assessment

SOL assess

$\begin{array}{lllll}-0.0014 & -0.0304 & -0.0152 & 0.0436 & 0.0033 \\ (-2.21)^{* * *} & (-2.78)^{* * *} & (-2.57)^{* * *} & (2.79)^{* * *} & (2.36)^{* *}\end{array}$

Notes: Figures in parentheses are z-statistics. The table summarizes information from Table B.3 in Appendix B.

Figure 1

Effect of Stay Duration on Return Intentions (Age $=35$ years)

\begin{tabular}{|l|l|l|l|l|l|l|}
\hline & & \\
\hline
\end{tabular}


Figure 2

Cumulative Probabilities: Stay Duration \& Return Intentions

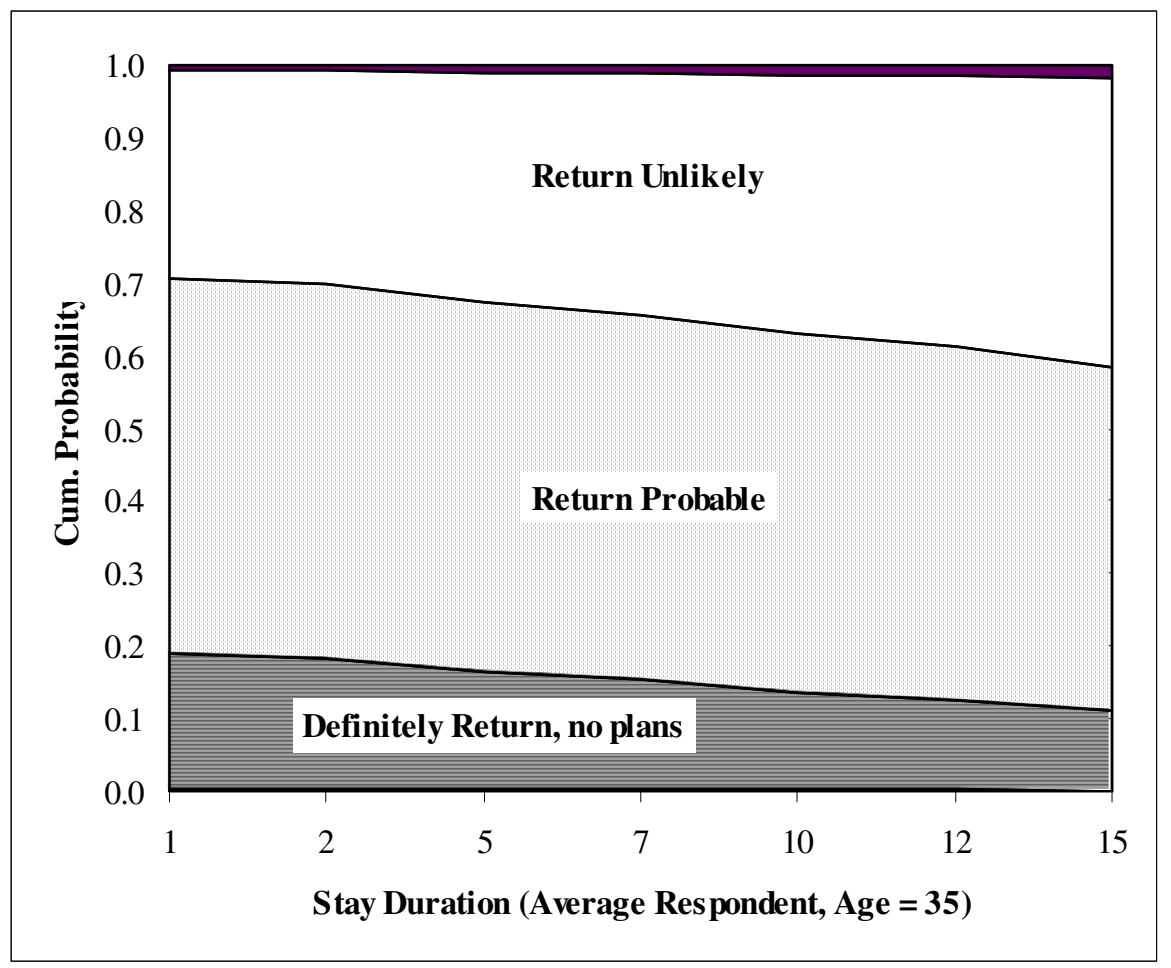

Figure 3

Effect of Work Experience in Current Country on Return Intentions

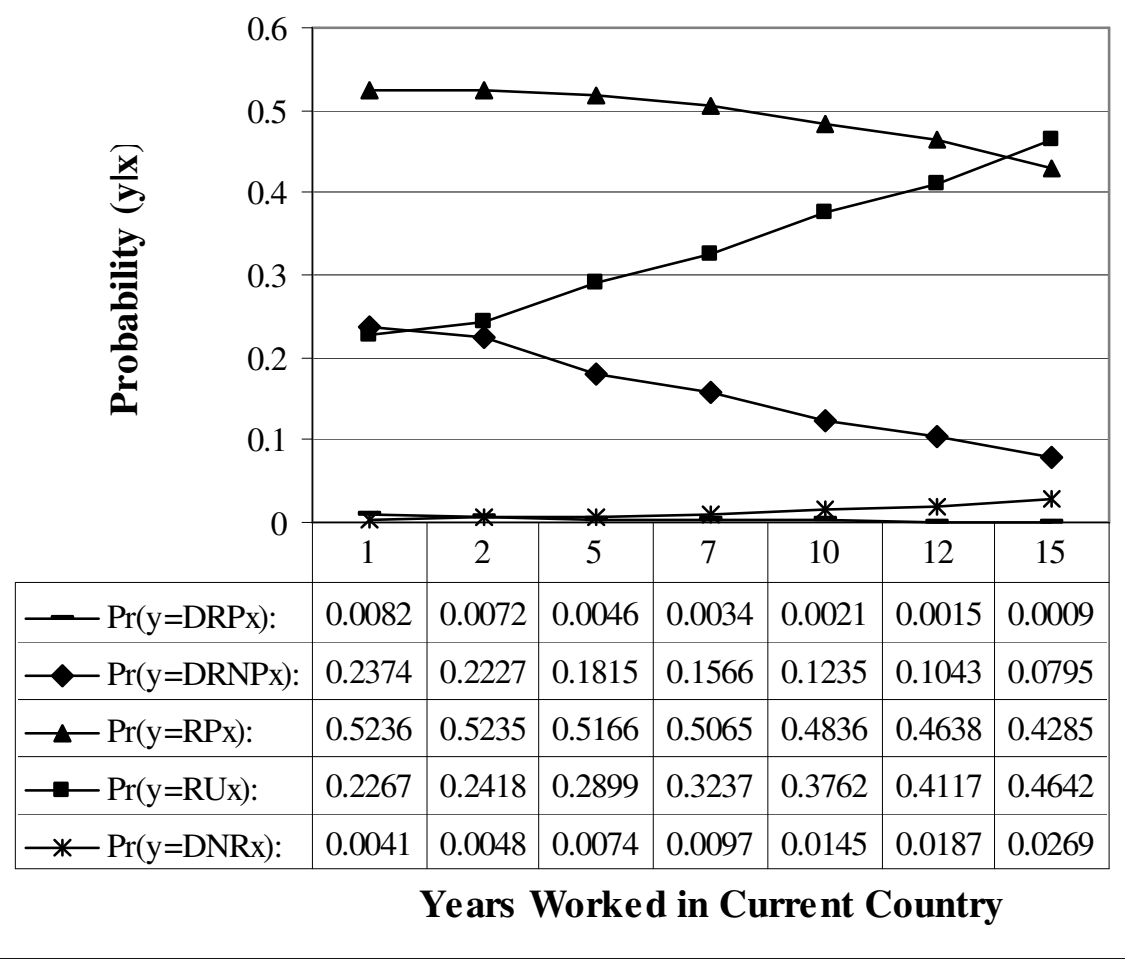


Figure 4

Cumulative Probabilities: Social Assessment of Life Abroad

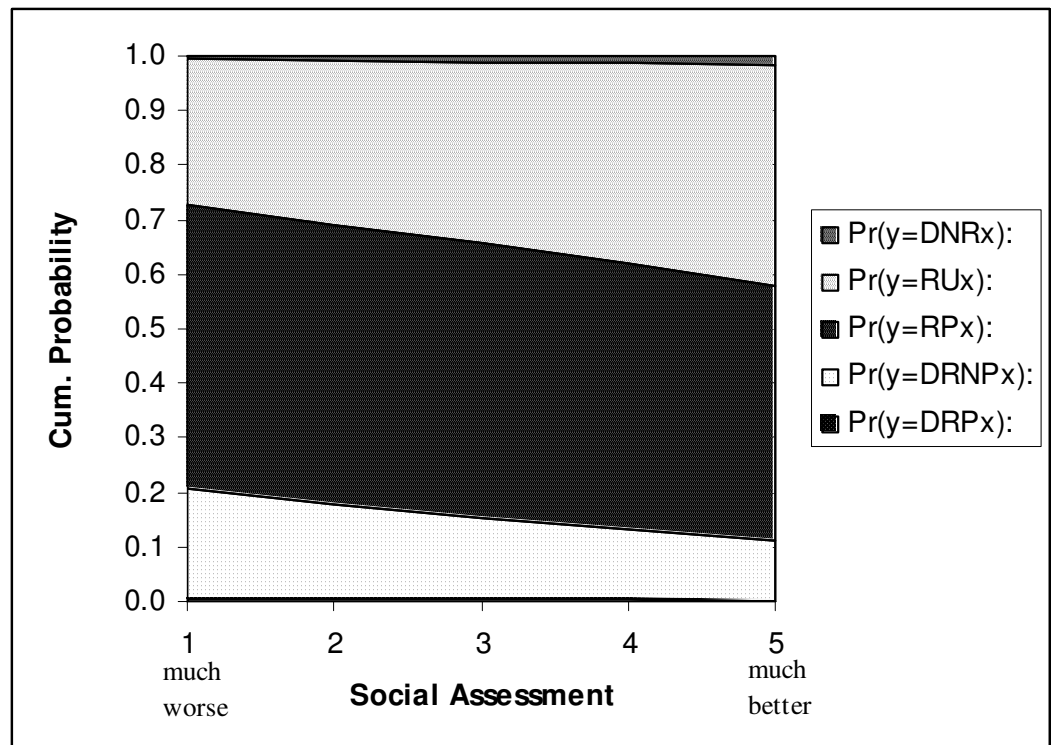

Figure 5

Cumulative Probabilities: SOL Assessment of Life Abroad

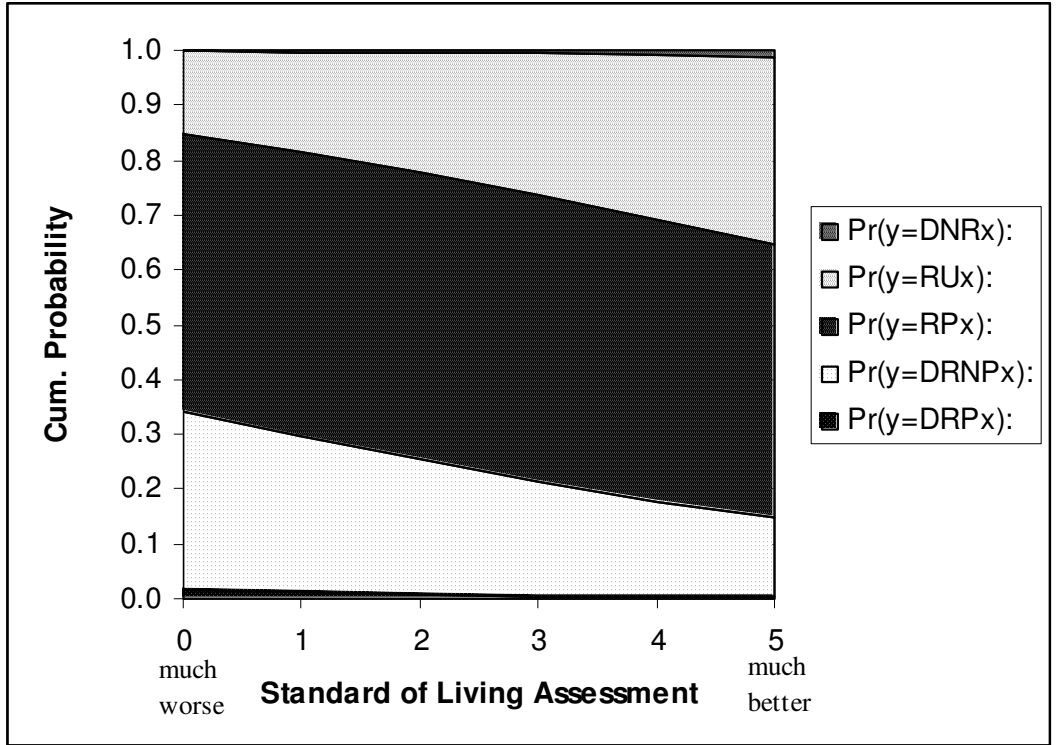


Figure 6

Effect of the Interaction between Age and Importance of Advanced Training Opportunities on the Probability of Not Returning ( $y=4$ or 5)

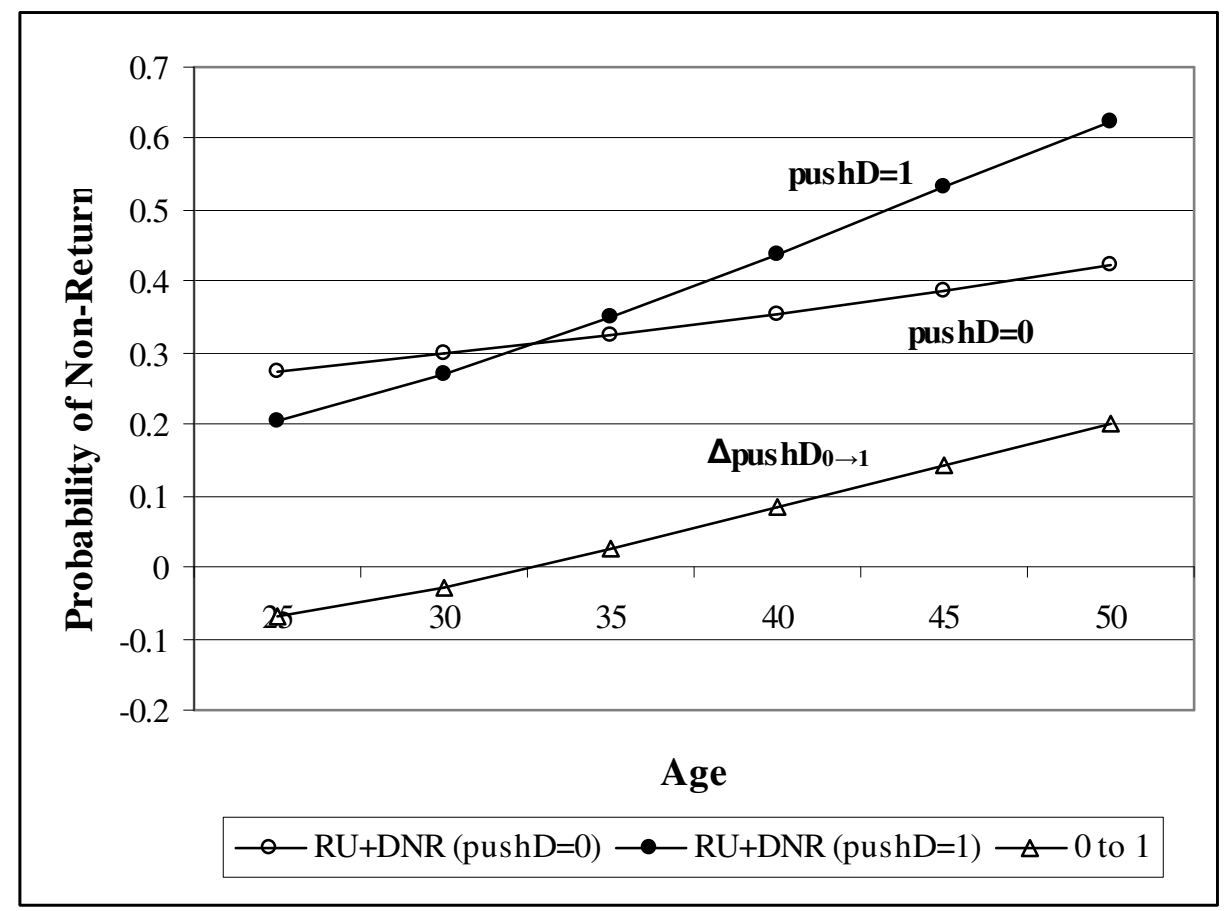

Figure 7

Effect of Stay Duration on Return Intentions, Students

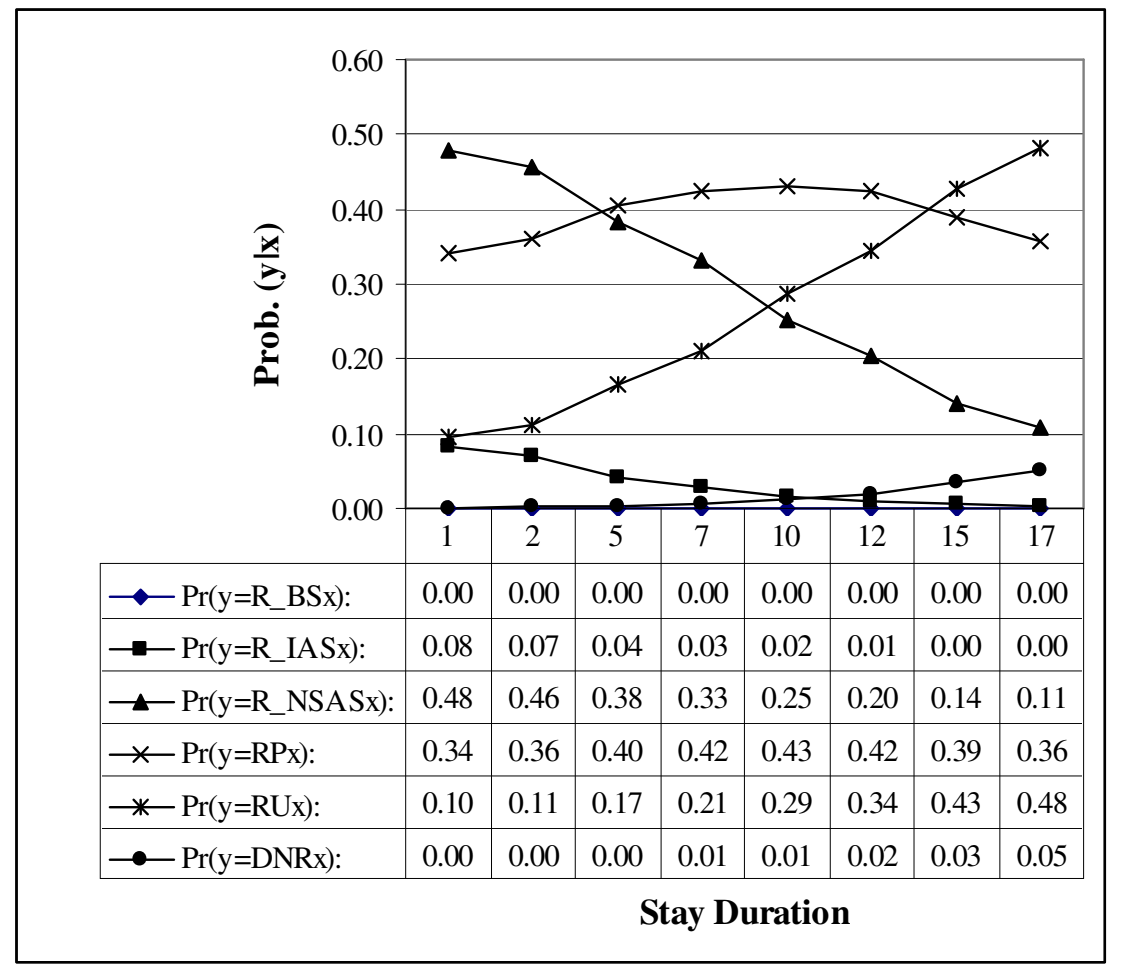

Notes: R_BS: return as soon as possible without completing studies; R_IAS: return immediately after completing studies; R_NSAS: definitely return but not soon after completing studies; RP: probably return RU: return unlikely; DNR: definitely not return. 
Table 3

Marginal Effects of Various Variables, Students

\begin{tabular}{lcccccc}
\hline \hline & $\begin{array}{c}R \_B S \\
\mathrm{y}=1\end{array}$ & $\begin{array}{c}R \_I A S \\
\mathrm{y}=2\end{array}$ & $\begin{array}{c}R \_N S A S \\
\mathrm{y}=3\end{array}$ & $\begin{array}{c}R P \\
\mathrm{y}=4\end{array}$ & $\begin{array}{c}R U \\
\mathrm{y}=5\end{array}$ & $\begin{array}{c}D N R \\
\text { Probabilities: }\end{array}$ \\
\hline Female $0 \rightarrow 1$ & -0.0002 & -0.0146 & -0.0344 & 0.0234 & 0.0251 & 0.0008 \\
& & & & & & \\
Return intentions: & & & & & & \\
init_STAY $\rightarrow$ init_UNSURE & 0.0003 & 0.0387 & 0.2582 & 0.0253 & -0.2857 & -0.0366 \\
init_UNSURE $\rightarrow$ init_RETURN & 0.0014 & 0.0663 & 0.1272 & -0.0999 & -0.0923 & -0.0029 \\
init_STAY $\rightarrow$ init_RETURN & 0.0017 & 0.105 & 0.3854 & -0.0746 & -0.3780 & -0.0007 \\
Family support: & & & & & & \\
Not Sup. $\rightarrow$ Somewhat Sup. & -0.0006 & -0.0305 & -0.0544 & 0.0462 & 0.0383 & 0.0011 \\
Somewhat Sup $\rightarrow$ Def. Sup. & -0.0003 & -0.0205 & -0.0579 & 0.0329 & 0.044 & 0.0017 \\
Not Sup. $\rightarrow$ Def. Sup. & -0.0009 & -0.051 & -0.1123 & 0.0791 & 0.0823 & 0.0028
\end{tabular}

Social Assessment: Worse or Much Worse

soc_W $0 \rightarrow 1$

$\begin{array}{llllll}0.0007 & 0.0424 & 0.0913 & -0.0661 & -0.0662 & -0.0021\end{array}$

Standard of Living

Assessment: Better or Much

Better

SOL_B $0 \rightarrow 1$

$\begin{array}{llllll}-0.0004 & -0.0219 & -0.0463 & 0.0344 & 0.0332 & 0.0010\end{array}$

Turkish Student Association membership

TSA_member $0 \rightarrow 1$

$\begin{array}{llllll}0.0004 & 0.0198 & 0.0462 & -0.0315 & -0.0337 & -0.0004\end{array}$

Reasons for going abroad:

Learn / improve language skills

whygo_A $0 \rightarrow 1$

$\begin{array}{llllll}0.0003 & 0.0162 & 0.0344 & -0.0254 & -0.0246 & -0.0008\end{array}$

Job requirement in Turkey

whygo_C $0 \rightarrow 1$

$\begin{array}{llllll}0.0006 & 0.0311 & 0.0672 & -0.0487 & -0.0485 & -0.0015\end{array}$

Insufficient facilities for

research

whygo_F $0 \rightarrow 1$

Prestige and advantages of

international study

whygo_G $0 \rightarrow 1$

Lifestyle preference

Whygo_H $0 \rightarrow 1$

To be with spouse / family

whygo_I $0 \rightarrow 1$

Get away from political

environment

whygo_K $0 \rightarrow 1$

Reason for choosing current

institution: job opportunities

DC_E $0 \rightarrow 1$

Reason for choosing current

institution: same location as

spouse

DC_F $0 \rightarrow 1$

Adjustment factor: previous experience

adj_A $0 \rightarrow 1$

Adjustment factor: Turkish

friends at institution

adj_F $0 \rightarrow 1$

$\begin{array}{llllll}-0.0002 & -0.0120 & -0.0283 & 0.0191 & 0.0206 & 0.0007\end{array}$

$\begin{array}{llllll}0.0001 & 0.0089 & 0.0215 & -0.0143 & -0.0157 & -0.0006\end{array}$

$\begin{array}{llllll}-0.0004 & -0.0238 & -0.0606 & 0.0380 & 0.0451 & 0.0017\end{array}$

$\begin{array}{llllll}0.0033 & 0.1067 & 0.1238 & -0.1411 & -0.0904 & -0.0021\end{array}$

$\begin{array}{llllll}-0.0007 & -0.0466 & -0.1315 & 0.0724 & 0.1021 & 0.0043\end{array}$

$\begin{array}{llllll}-0.0005 & -0.0316 & -0.0829 & 0.0504 & 0.0623 & 0.0024\end{array}$

$\begin{array}{llllll}-0.0006 & -0.0406 & -0.1291 & 0.0622 & 0.1033 & 0.0048\end{array}$

$\begin{array}{llllll}0.0004 & 0.0224 & 0.048 & -0.0353 & -0.0345 & -0.0011\end{array}$

$\begin{array}{llllll}0.0002 & 0.0152 & 0.0353 & -0.0242 & -0.0257 & -0.0009\end{array}$ 
Difficulties faced while abroad: unemployment

difabrdF $0 \rightarrow 1$

\begin{tabular}{|c|c|c|c|c|c|}
\hline 0.0007 & 0.0319 & 0.0573 & -0.0485 & -0.0404 & -0.0011 \\
\hline 0.0004 & 0.0285 & 0.0752 & -0.0455 & -0.0565 & -0.0021 \\
\hline 0.0035 & 0.1177 & 0.1472 & -0.1573 & -0.1085 & -0.0027 \\
\hline-0.0004 & -0.0237 & -0.0519 & 0.0374 & 0.0375 & 0.0012 \\
\hline-0.0003 & -0.0251 & -0.1043 & 0.0344 & 0.0902 & 0.0052 \\
\hline-0.0007 & -0.0395 & -0.0955 & 0.0624 & 0.0708 & 0.0025 \\
\hline-0.0007 & -0.0378 & -0.0723 & 0.0578 & 0.0514 & 0.0015 \\
\hline-0.0006 & -0.0298 & -0.0592 & 0.0461 & 0.0422 & 0.0012 \\
\hline-0.0006 & -0.0378 & -0.1057 & 0.0595 & 0.0813 & 0.0033 \\
\hline-0.0006 & -0.0387 & -0.1000 & 0.0612 & 0.0753 & 0.0029 \\
\hline 0.0012 & 0.0521 & 0.0843 & -0.0766 & -0.0595 & -0.0016 \\
\hline 0.0009 & 0.0400 & 0.0715 & -0.0604 & -0.0506 & -0.0014 \\
\hline
\end{tabular}

Respondent plans to work in academia

academic_b $0 \rightarrow 1$

Respondent has compulsory

academic requirement

compulsory $0 \rightarrow 1$

Push factor: being away from

research centers and recent

advances

pushE=1 Difference $0 \rightarrow 1$

Push factor: less than satisfying cultural / social life in Turkey

non-academic (academic_b $=0$ )

pushG $0 \rightarrow 1$

academic (academic_b=1)

pushG $0 \rightarrow 1$

Pull factor: higher level of income in host country

pull_A $0 \rightarrow 1$

Pull factor: more organized, ordered environment

pull_F $0 \rightarrow 1$

Pull factor: spouse's preference or job

pull_I $0 \rightarrow 1$

Last visit to Turkey decreased return intentions

lastvis $10 \rightarrow 1$

Last visit to Turkey increased return intentions

lastvis $30 \rightarrow 1$

Effect of Sept. 11: increased return intentions

sept11_inc $0 \rightarrow 1$

0.0009

$-0.0604$

.0014 


\section{Appendix A}

\section{A.1 Survey Methodology}

The Internet survey targeted two groups. The first group consisted of students at the undergraduate or graduate level studying at higher education institutions outside Turkey. The second group consisted of individuals with at least an undergraduate degree who were working abroad during the time of the survey. Separate questionnaires were constructed for these two groups. The initial part of the sampling strategy involved compiling a list of the names and e-mail addresses of potential participants that would serve as the sampling frame. The collection of potential participant names and contact information depended to a great extent on the existence and accessibility of student and personnel directories at institutions of higher learning and research centers, the existence of accessible and up-to-date alumni directories of Turkish universities, and the help of various Turkish associations abroad. Unfortunately, the reliance on internet search procedures in the construction of a list of potential participants inevitably set limitations on who could be reached. For example, individuals who were not members of any overseas Turkish associations, nor listed in any directories, and without e-mail address information (especially older participants) cannot be said to be adequately represented. Another limitation is that the search for survey participants concentrated on universities and associations in North America and England; time considerations did not permit expanding the search to other important destination countries, such as Germany in the case of students and the Middle East for skilled workers. The construction of a list of candidates, given the limited time frame for conducting the survey, could not be expected to be exhaustive and uncover each possible survey candidate.

An e-mail cover letter was sent to potential participants discovered through the search process described above. The cover letter explained the purpose of the study and contained a link to the web address of the survey page. Survey candidates were invited to participate in 
the study and to forward the cover e-mail letter to colleagues and friends who they believed would fit the targeted survey population. Asking the initial group of contacts to assist in reaching other potential participants who are in the targeted populations is a nonprobability sampling method known as "snowball" or "referral" sampling (Atkinson and Flint, 2001; Rea and Parker, 1997). This sampling strategy is used when the size and distribution of the populations are not known with certainty, and the probability that a given respondent will be picked as part of the sample is also unknown.

Referral sampling is a fast and efficient, but potentially biased, means of reaching the targeted populations, which introduces the possibility that non-participants may differ systematically from participants in terms of their characteristics and in their return intentions. For this reason, the survey results cannot be used to generalize to the full targeted populations. Nevertheless, the combination of internet search and "snowball" sampling resulted in a total of 1170 responses from Turkish students studying abroad, and 1282 responses from Turkish professionals working abroad. After eliminating responses from non-target populations and incomplete answers $^{\S \S \S}$, the number of valid responses totaled 1103 for the student survey, and 1238 for the survey of Turkish professionals. The sample sizes of the econometric models are smaller. This is due to the fact that response rates vary for some of the questions included as regressors in the estimated models.

\section{A.2 Choice of Estimation Methodology}

The ordered response model makes the assumption that the explanatory variables of the model will have the same impact across each of the categories of the dependent variable, which is known as the "parallel regression assumption" (Long and Freese, 2001). It could

\footnotetext{
$\$ \$$ Non-target populations included respondents from the Turkish Republic of Northern Cyprus and secondgeneration citizens of Turkish origin. Incomplete responses were eliminated on the basis of the extent of incompleteness (e.g. if a majority of the questions were left unanswered or if important portions of the survey were not filled out).
} 
well be that the coefficients of some or all of the explanatory variables are significantly different across each categorical choice, in which case alternative models must be considered, such as the multinomial logit model or generalized ordered logit / probit models. In the generalized ordered models, a separate parameter vector is estimated for each of the $J$ categories (e.g., $\beta^{1}, \beta^{2}, \ldots, \beta^{J}$ ). The parallel regression assumption may be tested with an approximate LR test or a Wald test (Long and Freese, 2001).

Although the parallel regression assumption is violated in both the student and professionals samples in our study, we base our results on the ordered probit model. Alternative estimation methodologies were employed, but we found that their shortcomings outweighed the advantages they offered. The drawback of using the multinomial logit model, for example, is that it does not preserve the inherent ordering of the return intention categories and therefore does not incorporate this information when estimating the coefficients of the explanatory variables. This results in a loss in the efficiency of the estimators (Long, 1997). While the generalized ordered logit model provides an alternative model that does preserve the ordering (e.g., it is a restricted version of the multinomial logit model), it is very sensitive to low frequency counts (e.g., small cell sizes). Thus, it is often necessary to combine the dependent variable categories that have low frequencies with adjacent categories in order for the estimation procedure to work. However, combining categories may also lead to a loss in information, especially if the underlying latent variable is multi-leveled or continuous. For example, while the "definitely not return" category has relatively few observations, it expresses a much more intense feeling about returning than the "unlikely to return" category, which is an important distinction within the context of the current study. As a result, we have chosen to present the results from the ordered probit model. A larger sample size and fewer explanatory variables would have made the use of generalized models more feasible. 


\section{A.3 Model Selection based on Estimation of Exploratory Ordered Probit Models}

In part A.2, the ordered probit model was chosen as an appropriate estimation method based on the characteristics of the dependent variable. In this section, we describe the model selection procedures used to determine the set of regressors to keep in the final estimation model. There are several things to note. One is that the set of possible regressors do not have the same number of valid points (cross-sections) because of missing responses. Including some of these regressors will come at the cost of reducing the sample size and thus the precision of the estimated parameters. On the other hand, excluding key variables will also compromise the fit of the estimated model.

An initial criterion for reducing the number of regressors is to exclude variables with a large number of missing responses that are not significantly associated with the dependent variable(s), based on the chi-square test of independence. Migration theory also serves to provide a guideline for keeping or excluding variables from the initial model.

After determining the initial set of explanatory variables the next stage in model selection involves adopting an appropriate strategy for choosing the best possible model—one that fits the data well and is relatively easy to interpret. The model may be complicated by non-linearities and interactions among the regressors. One approach to take would be to start from a saturated model—a model that incorporates all possible variables, interactions and higher-order terms - and to use a backward elimination procedure. At each step, terms that are not statistically significant individually and that also do not contribute significantly to the fit of the model are eliminated. The elimination procedure continues until further model reduction involves a significant deterioration in model fit. The advantage of this approach is that all of the reduced or pared down models are nested in the previous models so that one could use testing procedures, such as the likelihood ratio (LR) test, that are suitable for testing 
nested non-linear models. Otherwise, measures of fit based on information criteria must be used to compare non-nested models or models with different sample sizes.

One of the difficulties faced is that the response rates vary considerably across different sets of questions in the survey study. For example, there is a lower response rate for questions appearing at the end of the survey than for those appearing at the beginning. This means that starting from a saturated model with all possible sets of regressors, even with the initial reduction in the variable set, leads to a significant reduction in the sample size. Another approach that can be used is that of forward selection where the explanatory variables are added sequentially to the model. The criteria for adding a variable is based on whether the new variable significantly improves the fit of the model. With this strategy, the explanatory variables that have the greatest significant bivariate association with the dependent variable are used in the initial regression; then, more complicated models are gradually built up from this preliminary model. The disadvantage of this approach is that the final model may be sensitive to the initial set of regressors and to the order in which the remaining regressors are added. The ultimate strategy adopted in the current study is a combination of both approaches. 


\section{Appendix B}

Table B.1

Summary Statistics and Descriptions of the Variables used in the Final Model, Professionals $(n=1031)$

\begin{tabular}{|c|c|c|c|c|c|}
\hline Variable & Variable Descriptions & Mean & $\begin{array}{l}\text { Std } \\
\text { Dev. }\end{array}$ & Min & $\operatorname{Max}$ \\
\hline$y$ & $\begin{array}{l}\text { Dependent variable: return intentions } \\
\text { ( } 1=\text { definite return plans; } 2=\text { definite return, } \\
\text { no immediate plans; } 3=\text { return probable; } \\
4=\text { return unlikely; } 5=\text { definitely not return })\end{array}$ & 3.15 & 0.97 & 1 & 5 \\
\hline female & Gender of respondent ( $1=$ female $)$ & 0.28 & 0.45 & 0 & 1 \\
\hline init_UNSURE & Initial return intentions: Unsure (1=yes) & 0.36 & 0.48 & 0 & 1 \\
\hline init_RETURN & Initial return intentions: Return ( $1=$ yes) & 0.53 & 0.50 & 0 & 1 \\
\hline age & Age of respondent in 2001 & 35.04 & 8.90 & 22 & 72 \\
\hline agesq & Square of Age & 1307.99 & 722.14 & 484 & 5184 \\
\hline staydur & $\begin{array}{l}\text { Stay duration in current country of residence } \\
\text { (years) }\end{array}$ & 12.78 & 6.89 & 1 & 32 \\
\hline$y r s \_w r k d \_c c$ & Work experience in current country (years) & 6.84 & 6.88 & 1 & 31 \\
\hline spousenat & Married to a foreign spouse ( $1=$ yes $)$ & 0.15 & 0.36 & 0 & 1 \\
\hline$N W \exp T U R$ & $\begin{array}{l}\text { Respondent has no work experience in } \\
\text { Turkey (1=yes) }\end{array}$ & 0.32 & 0.47 & 0 & 1 \\
\hline FFTJloc3 & $\begin{array}{l}\text { Country of work after completing studies } \\
\text { abroad is Turkey ( } 1=\text { yes })\end{array}$ & 0.09 & 0.29 & 0 & 1 \\
\hline HDTURXPHD & $\begin{array}{l}\text { Respondent's highest degree is a PhD from a } \\
\text { Turkish university ( } 1=\text { yes })\end{array}$ & 0.04 & 0.20 & 0 & 1 \\
\hline social_assess & Assessment of social conditions abroad & 2.63 & 1.00 & 0 & 5 \\
\hline SOL_assess & Assessment of standard of living abroad & 4.48 & 0.81 & 0 & 5 \\
\hline fam_sup1 & $\begin{array}{l}\text { Family support for initial decision to go } \\
\text { abroad }\end{array}$ & 3.48 & 0.75 & 1 & 4 \\
\hline fam_sup2 & Family support for settling abroad & 4.39 & 1.51 & 1 & 6 \\
\hline academic2 & $\begin{array}{l}\text { Type of organization: Academic / Research } \\
\text { Center / Medical School }\end{array}$ & 0.27 & 0.44 & 0 & 1 \\
\hline whygo_C & Job requirement in Turkey & 0.22 & 0.42 & 0 & 1 \\
\hline whygo_F & Insufficient facilities, equipment for research & 0.27 & 0.44 & 0 & 1 \\
\hline whygo_G & Prestige and advantages of study abroad & 0.46 & 0.50 & 0 & 1 \\
\hline whygo_H & Lifestyle preference & 0.33 & 0.47 & 0 & 1 \\
\hline whygo_I & To be with spouse, family & 0.12 & 0.33 & 0 & 1 \\
\hline whygo_K & Get away from political environment & 0.32 & 0.47 & 0 & 1 \\
\hline pushC & Limited job opport. in specialty & 0.54 & 0.50 & 0 & 1 \\
\hline pushD & No opportunity for advanced training & 0.37 & 0.48 & 0 & 1 \\
\hline pushF & Lack of financial resources for business & 0.30 & 0.46 & 0 & 1 \\
\hline pushK & Economic instability & 0.85 & 0.35 & 0 & 1 \\
\hline pulle & Greater oppr. to develop specialty & 0.71 & 0.45 & 0 & 1 \\
\hline pullF & More organized, ordered envir. & 0.77 & 0.42 & 0 & 1 \\
\hline pullG & More satisfying social/cultural life & 0.26 & 0.44 & 0 & 1 \\
\hline pullH & Proximity to research and innov. centers & 0.42 & 0.49 & 0 & 1 \\
\hline pullI & Spouse's preference or job & 0.31 & 0.46 & 0 & 1 \\
\hline pullJ & Better educational opport. For children & 0.37 & 0.48 & 0 & 1 \\
\hline pullK & Need to finish /continue with current project & 0.16 & 0.36 & 0 & 1 \\
\hline
\end{tabular}


Table B.1 continued.

\begin{tabular}{|c|c|c|c|c|c|}
\hline Variable & Variable Description & Mean & $\begin{array}{r}\text { Std } \\
\text { Dev. }\end{array}$ & Min & Max \\
\hline pullL & Other & 0.05 & 0.21 & 0 & 1 \\
\hline Hdnew2 & $\begin{array}{l}\text { Field of Highest Degree: } \\
\text { Education/Languages/Social Sciences/Arts }\end{array}$ & 0.04 & 0.20 & 0 & 1 \\
\hline Hdnew3 & $\begin{array}{l}\text { Field of Highest Degree: } \\
\text { Engineering/Math/Science/Medicine }\end{array}$ & 0.66 & 0.47 & 0 & 1 \\
\hline$a d j \_A$ & Adjustment factor: previous experience & 0.43 & 0.50 & 0 & 1 \\
\hline adj_C & $\begin{array}{l}\text { Adjustment factor: support from TSA } \\
\text { (Turkish Student Association) }\end{array}$ & 0.05 & 0.21 & 0 & 1 \\
\hline difabrdA & Difficulties abroad: being away from family & 0.83 & 0.38 & 0 & 1 \\
\hline contrB2 & $\begin{array}{l}\text { Contribution to Turkey: Lobbying actitivies } \\
\text { on behalf of Turkey }\end{array}$ & 0.60 & 0.49 & 0 & 1 \\
\hline FTr4 & $\begin{array}{l}\text { Formal training received abroad is specific to } \\
\text { organization (1=yes) }\end{array}$ & 0.04 & 0.19 & 0 & 1 \\
\hline lastvisl & $\begin{array}{l}\text { Last visit to Turkey decreased return } \\
\text { intentions ( } 1=\text { yes) }\end{array}$ & 0.28 & 0.45 & 0 & 1 \\
\hline lastvis3 & $\begin{array}{l}\text { Last visit to Turkey increased return } \\
\text { intentions ( } 1=\text { yes) }\end{array}$ & 0.09 & 0.29 & 0 & 1 \\
\hline sept11_inc & $\begin{array}{l}\text { Effect of September 11, } 2001 \text { (1=increased } \\
\text { return intentions) }\end{array}$ & 0.10 & 0.30 & 0 & 1 \\
\hline
\end{tabular}


Table B.2

Summary Statistics and Descriptions of the Variables used in the Final Model, Students $(n=960)$

\begin{tabular}{|c|c|c|c|c|c|}
\hline Variable & Variable Descriptions & Mean & $\begin{array}{l}\text { Std } \\
\text { Dev. }\end{array}$ & Min & Max \\
\hline$y$ & $\begin{array}{l}\text { Dependent variable: return intentions } \\
\text { (1=return without completing studies; } \\
\text { 2=return immed. after compl. studies; } \\
3=\text { return probable; } 4=\text { return unlikely; } \\
5=\text { definitely not return) }\end{array}$ & 3.57 & 1.06 & 1 & 6 \\
\hline female & Gender of respondent ( $1=$ female $)$ & 0.39 & 0.49 & 0 & 1 \\
\hline age & Age of respondent in 2001 & 26.96 & 3.67 & 18 & 44 \\
\hline agesq & Square of Age & 740.40 & 207.08 & 324 & 1936 \\
\hline init_UNSURE & Initial return intentions: Unsure ( $1=$ yes) & 0.37 & 0.48 & 0 & 1 \\
\hline init_STAY & Initial return intentions: Return (1=yes) & 0.09 & 0.29 & 0 & 1 \\
\hline staydurl & $\begin{array}{l}\text { Stay duration in current country of residence } \\
\text { (years) }\end{array}$ & 2.79 & 2.31 & 0 & 13 \\
\hline FAMSUP1_S & $\begin{array}{l}\text { Family support for initial decision to go } \\
\text { abroad ( } 1=\text { supportive) }\end{array}$ & 0.95 & 0.21 & 0 & 1 \\
\hline FAMSUP2_SS & $\begin{array}{l}\text { Family support for settling abroad } \\
\text { (1=somewhat supportive) }\end{array}$ & 0.48 & 0.50 & 0 & 1 \\
\hline FAMSUP2_DS & $\begin{array}{l}\text { Family support for settling abroad } \\
\text { (1=definitely supportive) }\end{array}$ & 0.27 & 0.44 & 0 & 1 \\
\hline SOC_W & $\begin{array}{l}\text { Assessment of social conditions abroad } \\
(1=\text { much worse or worse })\end{array}$ & 0.44 & 0.50 & 0 & 1 \\
\hline$S O L \_B$ & $\begin{array}{l}\text { Assessment of standard of living abroad } \\
\text { (1=better or much better) }\end{array}$ & 0.69 & 0.46 & 0 & 1 \\
\hline TSA_member & $\begin{array}{l}\text { Turkish Student Association membership } \\
\text { (1=yes) }\end{array}$ & 0.57 & 0.49 & 0 & 1 \\
\hline res_USA & Current residence is USA ( $1=$ yes $)$ & 0.86 & 0.35 & 0 & 1 \\
\hline fieldnew1 & Current field of study: arch / econ / admin & 0.29 & 0.45 & 0 & 1 \\
\hline fieldnew3 & $\begin{array}{l}\text { Current field of study: engin / math / science } \\
\text { / medic }\end{array}$ & 0.58 & 0.49 & 0 & 1 \\
\hline div_sep & Respondent is divorced or separated & 0.02 & 0.15 & 0 & 1 \\
\hline not_married & Respondent has never married & 0.71 & 0.45 & 0 & 1 \\
\hline spousenat & Respondent is married to a foreign spouse & 0.02 & 0.14 & 0 & 1 \\
\hline whygo_A & Learn language, improve language skills & 0.25 & 0.44 & 0 & 1 \\
\hline whygo_C & Job requirement in Turkey & 0.41 & 0.49 & 0 & 1 \\
\hline whygo_F & Insufficient facilities, equipment for research & 0.45 & 0.50 & 0 & 1 \\
\hline whygo_G & Prestige and advantages of study abroad & 0.72 & 0.45 & 0 & 1 \\
\hline whygo_H & Lifestyle preference & 0.24 & 0.43 & 0 & 1 \\
\hline whygo_I & To be with spouse, family & 0.08 & 0.27 & 0 & 1 \\
\hline whygo_K & Get away from political environment & 0.25 & 0.44 & 0 & 1 \\
\hline$D C_{-} E$ & $\begin{array}{l}\text { Chose current institution because of job } \\
\text { opportunities }\end{array}$ & 0.26 & 0.44 & 0 & 1 \\
\hline$D C \_F$ & Chose current institution to be near spouse & 0.11 & 0.31 & 0 & 1 \\
\hline adj_A & Adjustment Factor: previous experience & 0.34 & 0.47 & 0 & 1 \\
\hline$a d j \_F$ & $\begin{array}{l}\text { Adjustment Factor: Turkish friends at } \\
\text { institution of study }\end{array}$ & 0.57 & 0.50 & 0 & 1 \\
\hline
\end{tabular}


Table B.2 continued.

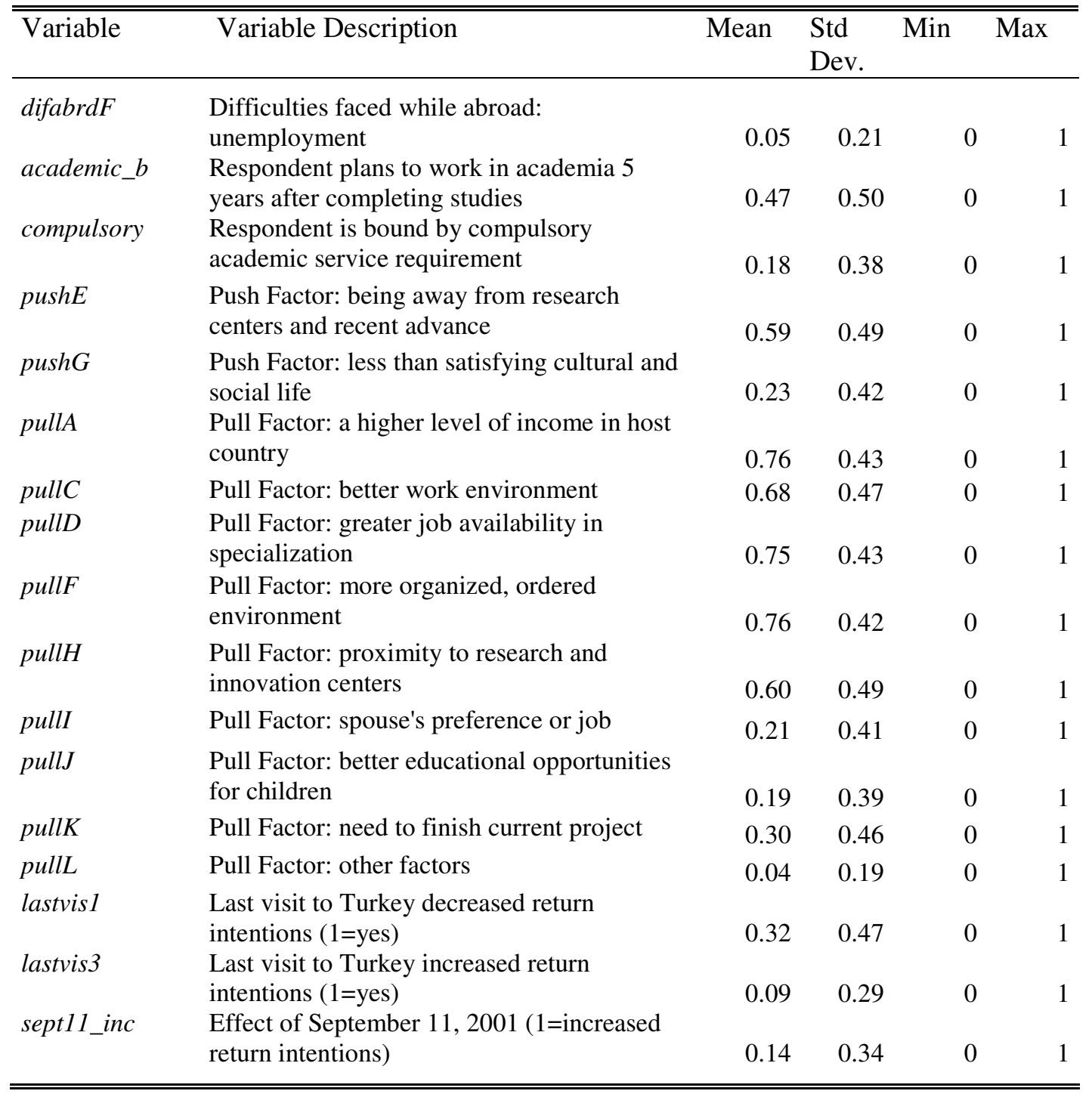


Table B.3

Estimation Results and Marginal Effects for Each Outcome, Ordered Probit Model, Professionals

\begin{tabular}{|c|c|c|c|c|c|c|c|}
\hline \multirow[b]{2}{*}{ Explanatory Variables } & \multirow[b]{2}{*}{$\boldsymbol{B}(\mathrm{a})$} & \multirow[b]{2}{*}{ z-value } & \multicolumn{5}{|c|}{$\mathrm{dy} / \mathrm{dx}$} \\
\hline & & & $\mathrm{y}=1$ & $\mathrm{y}=2$ & $y=3$ & $\mathrm{y}=4$ & $\mathrm{y}=5$ \\
\hline female (b) & 0.355 & $(2.40)^{* *}$ & -0.0031 & -0.0773 & -0.0518 & 0.1211 & 0.0111 \\
\hline init_UNSURE (b) & -0.950 & $(6.65) * * *$ & 0.0172 & 0.2433 & 0.0532 & -0.2928 & -0.0210 \\
\hline init_RETURN (b) & -1.323 & $(8.87)^{* * *}$ & 0.0186 & 0.2930 & 0.1480 & -0.4107 & -0.0488 \\
\hline age & 0.085 & $(1.11)$ & -0.0009 & -0.0199 & -0.0099 & 0.0286 & 0.0022 \\
\hline agesq & -0.001 & $(0.54)$ & 0.0000 & 0.0001 & 0.0001 & -0.0002 & 0.0000 \\
\hline staydur & 0.327 & $(3.40) * * *$ & -0.0034 & -0.0767 & -0.0382 & 0.1100 & 0.0083 \\
\hline yrs_wrkd_cc & 0.051 & $(3.23) * * *$ & -0.0005 & -0.0120 & -0.0060 & 0.0172 & 0.0013 \\
\hline AGExSTAYDUR & -0.012 & $(2.77) * * *$ & 0.0001 & 0.0029 & 0.0014 & -0.0042 & -0.0003 \\
\hline AGESQXSTAYDUR & 0.000 & $(2.05)^{* *}$ & 0.0000 & 0.0000 & 0.0000 & 0.0000 & 0.0000 \\
\hline spousnat2 (b) & 0.403 & $(3.43) * * *$ & -0.0030 & -0.0824 & -0.0674 & 0.1383 & 0.0145 \\
\hline NWexpTUR (b) & 0.213 & $(2.45)^{* *}$ & -0.0020 & -0.0482 & -0.0279 & 0.0722 & 0.0060 \\
\hline FFTJloc3 (b) & 0.475 & $(3.18)^{* * *}$ & -0.0031 & -0.0918 & -0.0874 & 0.1630 & 0.0194 \\
\hline HDTURXPHD (b) & -0.477 & $(2.31)^{* *}$ & 0.0093 & 0.1320 & 0.0113 & -0.1451 & -0.0075 \\
\hline social_assess & 0.101 & $(2.43)^{* *}$ & -0.0011 & -0.0237 & -0.0118 & 0.0340 & 0.0026 \\
\hline SOL_assess & 0.129 & $(2.80) * * *$ & -0.0014 & -0.0304 & -0.0152 & 0.0436 & 0.0033 \\
\hline fam_sup1 & -0.176 & $(2.82) * * *$ & 0.0019 & 0.0413 & 0.0206 & -0.0593 & -0.0045 \\
\hline fam_sup2 & 0.154 & $(5.46) * * *$ & -0.0016 & -0.0362 & -0.0181 & 0.0520 & 0.0039 \\
\hline academic 2 (b) & 0.078 & $(0.39)$ & -0.0008 & -0.0179 & -0.0096 & 0.0263 & 0.0021 \\
\hline whygo_C (b) & -0.190 & $(1.92)^{*}$ & 0.0023 & 0.0466 & 0.0181 & -0.0627 & -0.0043 \\
\hline whygo_F (b) & 1.536 & $(4.22) * * *$ & -0.0111 & -0.2538 & -0.2912 & 0.4475 & 0.1085 \\
\hline whygo_G (b) & -0.666 & $(1.69)^{*}$ & 0.0085 & 0.1595 & 0.0670 & -0.2177 & -0.0172 \\
\hline whygo_H (b) & 0.178 & $(2.14)^{* *}$ & -0.0017 & -0.0407 & -0.0229 & 0.0604 & 0.0049 \\
\hline whygo_I (b) & -0.454 & $(2.95) * * *$ & 0.0078 & 0.1217 & 0.0200 & -0.1416 & -0.0080 \\
\hline whygo_K (b) & 0.144 & $(1.69)^{*}$ & -0.0014 & -0.0331 & -0.0183 & 0.0489 & 0.0039 \\
\hline FxWHYGOC (b) & 0.347 & $(1.69)^{*}$ & -0.0025 & -0.0700 & -0.0598 & 0.1195 & 0.0128 \\
\hline FxWHYGOI (b) & 0.396 & $(1.73)^{*}$ & -0.0027 & -0.0782 & -0.0707 & 0.1363 & 0.0153 \\
\hline ACADxWHYGOG (b) & -0.465 & $(2.49) * *$ & 0.0082 & 0.1253 & 0.0189 & -0.1443 & -0.0080 \\
\hline AGExWHYGOF & -0.042 & $(4.14)^{* * *}$ & 0.0004 & 0.0098 & 0.0049 & -0.0140 & -0.0011 \\
\hline AGExWHYGOG & 0.021 & $(1.74)^{*}$ & -0.0002 & -0.0050 & -0.0025 & 0.0071 & 0.0005 \\
\hline pushC (b) & -0.070 & $(0.69)$ & 0.0007 & 0.0164 & 0.0083 & -0.0237 & -0.0018 \\
\hline pushD (b) & -0.966 & $(2.96) * * *$ & 0.0174 & 0.2466 & 0.0556 & -0.2979 & -0.0217 \\
\hline pushF (b) & -0.132 & $(1.65)^{*}$ & 0.0015 & 0.0318 & 0.0140 & -0.0442 & -0.0032 \\
\hline pushK (b) & 0.368 & $(3.38) * * *$ & -0.0056 & -0.0961 & -0.0228 & 0.1174 & 0.0071 \\
\hline pulle (b) & 0.263 & $(2.59) * * *$ & -0.0033 & -0.0648 & -0.0246 & 0.0867 & 0.0060 \\
\hline pullF (b) & 0.164 & $(1.76)^{*}$ & -0.0020 & -0.0399 & -0.0162 & 0.0543 & 0.0038 \\
\hline pullG (b) & 0.275 & $(3.05) * * *$ & -0.0025 & -0.0605 & -0.0390 & 0.0937 & 0.0083 \\
\hline pullH (b) & -0.215 & $(2.10)^{* *}$ & 0.0024 & 0.0512 & 0.0234 & -0.0718 & -0.0053 \\
\hline pullI (b) & 0.357 & $(3.58) * * *$ & -0.0033 & -0.0787 & -0.0504 & 0.1215 & 0.0109 \\
\hline pullJ (b) & 0.317 & $(3.67)^{* * *}$ & -0.0031 & -0.0716 & -0.0417 & 0.1073 & 0.0090 \\
\hline pullK (b) & -0.618 & $(4.99) * * *$ & 0.0122 & 0.1694 & 0.0159 & -0.1873 & -0.0102 \\
\hline pullL (b) & -0.460 & $(2.12)^{* *}$ & 0.0087 & 0.1264 & 0.0130 & -0.1407 & -0.0074 \\
\hline femalexpushC (b) & -0.257 & $(1.61)$ & 0.0035 & 0.0650 & 0.0204 & -0.0835 & -0.0054 \\
\hline femalexpullI (b) & -0.469 & $(2.73)^{* * *}$ & 0.0084 & 0.1267 & 0.0184 & -0.1454 & -0.0080 \\
\hline femalexpullK (b) & 0.380 & $(1.58)$ & -0.0026 & -0.0750 & -0.0679 & 0.1309 & 0.0146 \\
\hline femalexpullL (b) & 0.813 & $(1.99)^{* *}$ & -0.0034 & -0.1244 & -0.1877 & 0.2632 & 0.0523 \\
\hline ACADxpushC (b) & 0.387 & $(2.24) * *$ & -0.0029 & -0.0791 & -0.0650 & 0.1330 & 0.0140 \\
\hline ACADxpullE (b) & -0.292 & $(1.36)$ & 0.0039 & 0.0736 & 0.0236 & -0.0950 & -0.0062 \\
\hline ACADxpullH (b) & 0.493 & $(2.40)^{* *}$ & -0.0036 & -0.0991 & -0.0848 & 0.1688 & 0.0187 \\
\hline AGExpushD & 0.030 & $(3.14) * * *$ & -0.0003 & -0.0069 & -0.0035 & 0.0100 & 0.0008 \\
\hline HDnew2 (b) & 0.544 & $(3.03) * * *$ & -0.0031 & -0.0988 & -0.1089 & 0.1857 & 0.0252 \\
\hline HDnew3 (b) & 0.270 & $(3.29) * * *$ & -0.0033 & -0.0658 & -0.0266 & 0.0893 & 0.0063 \\
\hline $\operatorname{adj} \_A(b)$ & -0.268 & $(3.58) * * *$ & 0.0030 & 0.0640 & 0.0293 & -0.0896 & -0.0067 \\
\hline adj_C (b) & -0.248 & $(1.51)$ & 0.0036 & 0.0639 & 0.0174 & -0.0800 & -0.0049 \\
\hline difabrdA(b) & -0.217 & $(2.21)^{* *}$ & 0.0019 & 0.0475 & 0.0312 & -0.0741 & -0.0066 \\
\hline contrB2 (b) & -0.390 & $(4.99) * * *$ & 0.0039 & 0.0882 & 0.0507 & -0.1316 & -0.0112 \\
\hline
\end{tabular}




\begin{tabular}{lclccccc} 
FTr4 (b) & 0.366 & $(1.90)^{*}$ & -0.0025 & -0.0726 & -0.0651 & 0.1262 & 0.0140 \\
lastvis1 (b) & 0.154 & $(1.87)^{*}$ & -0.0015 & -0.0350 & -0.0200 & 0.0522 & 0.0043 \\
lastvis3 (b) & -0.716 & $(5.64)^{* * *}$ & 0.0175 & 0.2044 & -0.0054 & -0.2065 & -0.0100 \\
Sept11_inc (b) & -0.262 & $(2.06)^{* *}$ & 0.0037 & 0.0671 & 0.0191 & -0.0847 & -0.0053 \\
& & & & & & \\
\hline \hline
\end{tabular}

Notes: * significant at $10 \%$; ** significant at $5 \% ; * * *$ significant at $1 \%$;

(a) Robust z-statistics in parentheses; Observations $=1031$; Log-likelihood $=-1028.82 ;$ LR chi2(59) $=651.57$; Maximum Likelihood R2 = 0.527; McFadden's Adjusted R2 = 0.228; McKelvey-Zavoina R2 = 0.583; AIC = 2.118; $\mathrm{BIC}=-4658.626$

(b) dy/dx is for discrete change of dummy variable from 0 to 1 . 
Table B.4

Estimation Results and Marginal Effects for each Outcome, Ordered Probit Model, Students

\begin{tabular}{|c|c|c|c|c|c|c|c|c|}
\hline \multirow{2}{*}{$\begin{array}{l}\text { Explanatory } \\
\text { Variables }\end{array}$} & \multirow[b]{2}{*}{$\beta(a)$} & \multirow[b]{2}{*}{ z-statistic } & \multicolumn{6}{|c|}{$\mathrm{dy} / \mathrm{dx}$} \\
\hline & & & $\mathrm{y}=1$ & $\mathrm{y}=2$ & $\mathrm{y}=3$ & $\mathrm{y}=4$ & $\mathrm{y}=5$ & $y=6$ \\
\hline female(b) & 0.124 & $(1.61)$ & 0.000 & -0.015 & -0.034 & 0.023 & 0.025 & 0.001 \\
\hline age & 0.036 & $(0.34)$ & 0.000 & -0.004 & -0.010 & 0.007 & 0.007 & 0.000 \\
\hline agesq & -0.001 & $(0.60)$ & 0.000 & 0.000 & 0.000 & 0.000 & 0.000 & 0.000 \\
\hline init_UNSURE(b) & 0.495 & $(5.66)^{* * *}$ & -0.001 & -0.055 & -0.139 & 0.085 & 0.106 & 0.004 \\
\hline init_STAY(b) & 1.434 & $(8.55)^{* * *}$ & -0.001 & -0.077 & -0.379 & -0.005 & 0.404 & 0.057 \\
\hline staydur1 & 0.087 & $(4.26)^{* * *}$ & 0.000 & -0.010 & -0.024 & 0.017 & 0.017 & 0.001 \\
\hline FAMSUP2_SS(b) & 0.216 & $(2.55)^{* *}$ & 0.000 & -0.026 & -0.060 & 0.041 & 0.043 & 0.001 \\
\hline FAMSUP2_DS(b) & 0.415 & $(3.80)^{* * *}$ & -0.001 & -0.044 & -0.119 & 0.068 & 0.092 & 0.004 \\
\hline soc_W(b) & -0.339 & $(4.49)^{* * *}$ & 0.001 & 0.042 & 0.091 & -0.066 & -0.066 & -0.002 \\
\hline SOL_B(b) & 0.172 & $(1.99)^{* *}$ & 0.000 & -0.022 & -0.046 & 0.034 & 0.033 & 0.001 \\
\hline TSA_member(b) & -0.167 & $(2.15)^{* *}$ & 0.000 & 0.020 & 0.046 & -0.031 & -0.034 & -0.001 \\
\hline div_sep(b) & 0.542 & $(2.44)^{* *}$ & -0.001 & -0.044 & -0.163 & 0.062 & 0.138 & 0.008 \\
\hline not_married(b) & 0.181 & $(1.60)$ & 0.000 & -0.023 & -0.048 & 0.036 & 0.035 & 0.001 \\
\hline spousenat(b) & 0.545 & (1.64) & -0.001 & -0.044 & -0.163 & 0.062 & 0.139 & 0.008 \\
\hline whygo_A(b) & -0.127 & $(1.47)$ & 0.000 & 0.016 & 0.034 & -0.025 & -0.025 & -0.001 \\
\hline whygo_C(b) & -0.248 & $(3.05)^{* * *}$ & 0.001 & 0.031 & 0.067 & -0.049 & -0.048 & -0.002 \\
\hline whygo_F(b) & 0.220 & $(2.14)^{* *}$ & 0.000 & -0.026 & -0.061 & 0.042 & 0.045 & 0.001 \\
\hline whygo_G(b) & -0.241 & $(2.12)^{* *}$ & 0.000 & 0.027 & 0.068 & -0.043 & -0.051 & -0.002 \\
\hline whygo_H(b) & 0.213 & $(2.06)^{* *}$ & 0.000 & -0.024 & -0.061 & 0.038 & 0.045 & 0.002 \\
\hline whygo_I(b) & -0.331 & $(1.65)^{*}$ & 0.001 & 0.049 & 0.080 & -0.072 & -0.056 & -0.001 \\
\hline whygo_K(b) & 0.280 & $(2.42)^{* * *}$ & 0.000 & -0.031 & -0.080 & 0.049 & 0.060 & 0.002 \\
\hline ACADxwhygoF(b) & -0.252 & $(1.67)^{*}$ & 0.001 & 0.033 & 0.066 & -0.052 & -0.047 & -0.001 \\
\hline ACADxwhygoG(b) & 0.349 & $(2.13)^{* *}$ & -0.001 & -0.039 & -0.099 & 0.061 & 0.075 & 0.003 \\
\hline ACADxwhygoI(b) & -0.604 & $(2.67)^{* * *}$ & 0.003 & 0.107 & 0.118 & -0.140 & -0.086 & -0.002 \\
\hline ACADxwhygoK(b) & 0.370 & $(2.03)^{* *}$ & -0.001 & -0.036 & -0.109 & 0.056 & 0.085 & 0.004 \\
\hline DC_E(b) & 0.290 & $(3.58)^{* * *}$ & -0.001 & -0.032 & -0.083 & 0.050 & 0.062 & 0.002 \\
\hline DC_F(b) & 0.436 & $(2.82)^{* * *}$ & -0.001 & -0.041 & -0.129 & 0.062 & 0.103 & 0.005 \\
\hline $\operatorname{adj} \_A(b)$ & -0.178 & $(2.19)^{* *}$ & 0.000 & 0.022 & 0.048 & -0.035 & -0.034 & -0.001 \\
\hline adj_F(b) & -0.128 & $(1.64)$ & 0.000 & 0.015 & 0.035 & -0.024 & -0.026 & -0.001 \\
\hline difabrdF(b) & -0.227 & $(1.33)$ & 0.001 & 0.032 & 0.057 & -0.048 & -0.040 & -0.001 \\
\hline academic_b(b) & -0.430 & $(2.51)^{* *}$ & 0.001 & 0.053 & 0.116 & -0.082 & -0.085 & -0.003 \\
\hline compulsory(b) & -0.705 & $(5.75)^{* * *}$ & 0.004 & 0.118 & 0.147 & -0.157 & -0.108 & -0.003 \\
\hline $\operatorname{pushE}(b)$ & 0.191 & $(2.25)^{* *}$ & 0.000 & -0.024 & -0.052 & 0.037 & 0.038 & 0.001 \\
\hline pushG(b) & -0.061 & $(0.56)$ & 0.000 & 0.008 & 0.017 & -0.012 & -0.012 & 0.000 \\
\hline pullA(b) & 0.279 & $(3.27)^{* * *}$ & -0.001 & -0.038 & -0.072 & 0.058 & 0.051 & 0.001 \\
\hline pullC(b) & -0.104 & $(1.26)$ & 0.000 & 0.012 & 0.029 & -0.019 & -0.021 & -0.001 \\
\hline pullD(b) & 0.092 & $(1.02)$ & 0.000 & -0.011 & -0.025 & 0.018 & 0.018 & 0.001 \\
\hline pullF(b) & 0.225 & $(2.50)^{* *}$ & -0.001 & -0.030 & -0.059 & 0.046 & 0.042 & 0.001 \\
\hline $\operatorname{pullI}(\mathrm{b})$ & 0.365 & $(3.53)^{* * *}$ & -0.001 & -0.038 & -0.106 & 0.060 & 0.081 & 0.003 \\
\hline $\operatorname{pullJ}(\mathrm{b})$ & -0.116 & $(1.12)$ & 0.000 & 0.015 & 0.031 & -0.023 & -0.022 & -0.001 \\
\hline pullK(b) & -0.087 & $(0.77)$ & 0.000 & 0.011 & 0.024 & -0.017 & -0.017 & -0.001 \\
\hline pullL(b) & -0.469 & $(1.53)$ & 0.002 & 0.077 & 0.102 & -0.107 & -0.073 & -0.002 \\
\hline ACADxpushG(b) & 0.403 & $(2.12)^{* *}$ & -0.001 & -0.038 & -0.119 & 0.058 & 0.095 & 0.004 \\
\hline ACADxpullK(b) & -0.188 & $(1.18)$ & 0.000 & 0.025 & 0.049 & -0.039 & -0.035 & -0.001 \\
\hline ACADxpullL(b) & 0.864 & $(1.84)^{*}$ & -0.001 & -0.055 & -0.253 & 0.048 & 0.240 & 0.020 \\
\hline lastvis1(b) & 0.352 & $(3.99)^{* * *}$ & -0.001 & -0.039 & -0.100 & 0.061 & 0.075 & 0.003 \\
\hline lastvis3(b) & -0.350 & $(2.91)^{* * *}$ & 0.001 & 0.052 & 0.084 & -0.077 & -0.059 & -0.002 \\
\hline sept11_inc(b) & -0.284 & $(2.79)^{* * *}$ & 0.001 & 0.040 & 0.072 & -0.060 & -0.051 & -0.001 \\
\hline
\end{tabular}


Notes: $*$ significant at $10 \% ; * *$ significant at $5 \% ; * * *$ significant at $1 \%$;

(a) Robust z-statistics in parentheses; Observations $=960$; Log-likelihood $=-1073.44$; LR chi2(48)= 583.83; Maximum Likelihood R2 = 0.491; McFadden's Adjusted R2 = 0.194; McKelvey-Zavoina R2 = 0.535; AIC = 2.347; $\mathrm{BIC}=-4081.431$.

(b) $\mathrm{dy} / \mathrm{dx}$ is for discrete change of dummy variable from 0 to 1 . 